\title{
La contabilidad del desarrollo insostenible. Un análisis de contracuentas sobre la pérdida de biodiversidad en el caso JBS Brasil*
}

Accounting for unsustainable development. A counter-accounting analysis of biodiversity loss in the JBS Brazil case

A contabilidade do desenvolvimento insustentável. Uma análise das contra-contas sobre a perda de biodiversidade no caso JBS Brasil

Luis Fernando Valenzuela-Jiménez

Universidad Nacional de Colombia, Colombia

DOI: https://doi.org/10.11144/Javeriana.cc22.cdia

ORCID: https://orcid.org/0000-0001-6186-6682

Recibido: 14/09/2020

Yuli Marcela Suárez-Rico ${ }^{\text {a }}$

Aceptado: 08/09/2021

Universidad Cooperativa de Colombia, Colombia

Publicado: 31/12/2021

ymsuarezr@unal.edu.co

ORCID: https://orcid.org/0000-0002-3754-6600

\section{Resumen:}

Este estudio muestra la responsabilidad que la multinacional JBS S.A., un gran productor de proteína animal en el mundo, ha tenido sobre la pérdida de biodiversidad por deforestación en Brasil, por más de diez años. Para ello se construye una contracuenta basada en información de diversas ONG y de organizaciones sociales que evidencian cómo los reportes de sostenibilidad de las grandes compañías maquillan comportamientos que llevan a la insostenibilidad teniendo como punto de referencia una perspectiva teórica crítica de la contabilidad y tomando como base puntual la literatura que aborda las posibilidades de la contabilidad para la emancipación, en diálogo con literatura latinoamericana sobre temas ambientales y del desarrollo. El trabajo se basa en teorías emergentes bajo el concepto de contracontabilidad, que plantean la débil efectividad del desarrollo sostenible. Los hallazgos de esta investigación evidencian las posibilidades de nuevos discursos contables para la transformación social y ambiental en los países latinoamericanos a través de maneras alternativas de rendición de cuentas, ampliando la literatura contable sobre el rol de la contabilidad en la problemática ambiental, en tanto los informes tradicionales y oficiales sólo muestran la cara conveniente a los intereses de la empresa que reporta.

Códigos JEL: M14, M41.

Palabras clave: Desarrollo sostenible, insostenibilidad, contracuentas, biodiversidad.

\section{Abstract:}

This study shows the responsibility that multinational JBS S.A., a large producer of animal protein, has had on the loss of biodiversity due to deforestation in Brazil for over than 10 years. To do this, a counter-account is constructed based on information from various NGOs and social organizations that show how the sustainability reports of large companies make up behaviors that lead to unsustainability. A critical theoretical accounting perspective serves as a point of reference, and the study takes specific literature that addresses the possibilities of accounting for emancipation, in dialogue with Latin American literature on environmental and development issues, as a basis. The work is based on emerging theories under the concept of counter-accounting, which raise the weak effectiveness of sustainable development. The findings of this research show the possibilities of new accounting discourses for social and environmental transformation in Latin American countries through alternative forms of accountability. This expands the accounting literature on the role of accounting in environmental issues, while traditional and official reports only show the side which is most convenient to the interests of the reporting company.

JEL Codes: M14, M41.

Keywords: Sustainable development, unsustainability, counter accounts, biodiversity.

\section{Resumo:}

Este estudo mostra a responsabilidade que a multinacional JBS S.A., grande produtor de proteína animal no mundo, tem sobre a perda de biodiversidade devido ao desmatamento no Brasil, há mais de 10 anos. Para tanto, é construída uma contra-conta a partir de informações de diversas ONG e organizaçôes sociais que mostram como os relatórios de sustentabilidade de grandes

Notas de autor

$$
\text { a Autora de correspondencia. E-mail: ymsuarezr@unal.edu.co }
$$


empresas configuram comportamentos que levam à insustentabilidade, tomando como referência uma perspectiva teórica crítica da contabilidade e tomando como base uma literatura específica que aborda as possibilidades de contabilização da emancipação, em diálogo com a literatura latino-americana sobre questões ambientais e de desenvolvimento. O trabalho é baseado em teorias emergentes sob o conceito de contra-contabilidade, que apresentam a fraca eficácia do desenvolvimento sustentável. Os achados desta pesquisa mostram as possibilidades de novos discursos contábeis para a transformação socioambiental nos países latinoamericanos por meio de formas alternativas de accountability, ampliando a literatura contábil sobre o papel da contabilidade nos problemas ambientais, enquanto os relatórios tradicionais e oficiais mostram apenas o rosto que atende aos interesses da empresa relatora.

Códigos JEL: M14, M41.

Palavras-chave: Desenvolvimento sustentável, insustentabilidade, contracuentas, biodiversidade.

\section{Introducción}

El desarrollo sostenible es el concepto icónico del capitalismo actual, cubre tanto asuntos económicos como sociales y ambientales (Comisión Mundial del Medio ambiente y del Desarrollo, 1988). Sin embargo, en la práctica cotidiana la dimensión económica prima sobre las otras dos en la sociedad capitalista que promueve la producción, el consumo, las ventas y el beneficio al infinito, frente a lo adecuado que sería lo limitado, incluso el decrecimiento (Gorz, 2008; Latouche, 2008; Meadows, Meadows, Randers et al., 1976; Taibo, 2010), con un modelo económico irracional que privilegia la ganancia máxima e ilimitada para unos pocos grupos empresariales (Bakan, 2006; Max-Neef \& Smith, 2014), los mismos que generan desigualdades insostenibles (Piketty, 2014) y problemas ambientales con industrias contaminantes o causantes de deforestación, en regiones como la Amazonía, que evidencian una insostenibilidad del desarrollo irónicamente promovido como la mejor alternativa (Teitelbaum, 2010). Estos problemas son de interés y atención creciente por parte de la disciplina contable y sus profesionales (Bebbington \& Unerman, 2018; Gallhofer \& Haslam, 1997; Gray, Brennan, \& Malpas, 2014; Lehman, Marcia, \& Agyemang, 2016; Moneva, Archel, \& Correa, 2006). Sobre estas bases teóricas planteamos el artículo que cuestiona el rol de la contabilidad en la insostenibilidad del desarrollo, a la luz de la literatura reciente, y amparado en la corriente de la contracontabilidad.

Una cuestión de preocupación es que las empresas no asumen responsabilidad por los daños que causan y la contabilidad juega un papel legitimador de tales oprobios (Richardson, 2009), de manera que se externalizan los perjuicios, con sistemas contables que ignoran los hechos (Cooper \& Morgan, 2013; Denedo, Thomson, \& Yonekura, 2017; Thomson, Dey, \& Russell, 2010; Tombs \& Whyte, 2015). No obstante, con la contracontabilidad es viable intentar neutralizar parte de los problemas que vive la sociedad y el ambiente mediante diversos mecanismos prácticos de participación activa por parte de variados grupos de interés, tal como se ha venido proponiendo en las últimas décadas usando las contracuentas (Boiral, 2013, 2016; Gallhofer, Haslam, Monk et al., 2006) y expresiones alternativas como contabilidad externa, nuevas cuentas, cuentas en la sombra o silenciosas, contabilidad habilitante, contabilidad dialógica, contabilidad emancipatoria, en un intento de refrescar el rol de la contabilidad (Apostol, 2010; Brown \& Dillard, 2015; Gallhofer \& Haslam, 2003; Gray et al., 2014; Lehman et al., 2016; Thomson et al., 2010; Vinnari \& Laine, 2017).

Aunque el desarrollo sostenible dice buscar el equilibrio económico y socioambiental los resultados son contrarios a sus prédicas, pues perpetúa asimetrías de bienestar y desigualdad (De Venanzi, 2002; Naredo, 2010; Piketty, 2014), dando ocasión a la emergencia de respuestas contestatarias y estrategias de resistencia por parte de diversidad de actores sociales (Brown \& Dillard, 2015; Conde, 2016).

Autores de diversas nacionalidades han propuesto el uso de la contracontabilidad y las contracuentas como paliativo al desequilibrio informativo sobre la situación social y ambiental, cuando se trata de mostrar la realidad de las acciones corporativas (Gallhofer et al., 2006; Sikka, 2006; Vinnari \& Laine, 2017). Además, se han realizado exhortaciones a seguir tratando los problemas epistemológicos de la contabilidad tradicional 
(Gallhofer \& Haslam, 2003; Paisey y Paisey, 2006). Sin embargo, son insuficientes los estudios que se han adelantado sobre la realidad latinoamericana en materia social y ambiental en relación con el desarrollo sostenible y la contracontabilidad (Conde, 2016; Contrafatto, Thomson, \& Monk, 2015), situación injusta para una región con gran potencial natural, pero agobiada por la pobreza y víctima del saqueo a la que es sometida por el sistema capitalista, lo que justifica emprender investigaciones similares a las realizadas en otros países (Apostol, 2010; Conde, 2016).

También es necesario que se conozcan las consideraciones y el pensamiento latinoamericano sobre la condición inequitativa que vive la región con ocasión del paradigma del desarrollo sostenible y exorcizar su concepto (Ángel Maya, 2003), porque su propósito degrada el ambiente y destruye la naturaleza (Leff, 2002).

Este trabajo extiende la reflexión sobre la importancia y necesidad de la contracontabilidad, particularmente estudiando el problema de la pérdida de biodiversidad en Latinoamérica debido a los graves impactos por la operación de grandes corporaciones, más aún si se ha constatado que sobre esta región falta mucho por revelar (Dussel, 2001; Escobar, 2007, 2014a; Noguera, 2004). Además, en materia de desarrollo sostenible los indicadores demuestran pésimos resultados, configurando una crisis socioambiental que ha derivado en degradación (Ángel Maya, 1996; Escobar, 2014b; Leff, 1986, 2008; Quijano, 2014).

Con este escenario, el trabajo pretende analizar la compleja operación de una corporación multinacional que ocasiona múltiples conflictos e impactos negativos sobre la sociedad y el ambiente, con lo que se contribuye al conocimiento sobre la realidad latinoamericana y al reclamo por la pérdida de biodiversidad (Müller, 2020). El caso estudiado aborda la responsabilidad de la multinacional brasileña JBS S.A, uno de los líderes mundiales de producción de proteína animal, en la pérdida de biodiversidad por deforestación en el Brasil, para lo cual se usa el concepto de "arena", siguiendo a Renn (1992) y Georgakopulos \& Thomson (2008), como un marco útil para comprender y representar a los actores involucrados. En la contracuenta que se construye, se evidencia el impacto negativo ocasionado sobre la biodiversidad en la Amazonía, la región donde opera la multinacional estudiada

\section{Biodiversidad, contabilidad y contracontabilidad}

La pérdida de biodiversidad es uno de los tres problemas más sensibles en materia ambiental, junto con el cambio climático y la destrucción de la capa de ozono (Estevan \& Naredo, 2009; Myers, Mittermeier, Mittermeie et al., 2000). Este problema es tan crítico que se asocia con una extinción masiva de especies para calificarla como la sexta extinción (Jiménez, 2008). La destrucción ambiental y el deterioro de justicia social ocasionados por el sistema capitalista y su engranaje corporativo han sido estudiados por connotados pensadores contables (Bebbington \& Gray, 2001; Gray, 2006; Tinker \& Gray, 2003) y durante lo corrido del presente siglo se ha cuestionado ampliamente el alcance que tiene la información contable no financiera para la rendición de cuentas, dado que ha sido captada por la lógica instrumental de la gestión corporativa, bien sea desde el punto de vista estratégico o desde el punto de vista de la legitimación (Bebbington, Larrinaga, \& Moneva, 2008; Cho, Laine, Roberts et al., 2015; Gray, 2010; Hahn \& Lülfs, 2014; Moneva et al., 2006; Spence, Husillos, y Correa-Ruiz, 2010).

Aunado a lo anterior, las corporaciones que causan los daños ambientales y sociales utilizan diversos mecanismos para desvirtuar las acusaciones que recaen sobre ellas (Boiral, 2013; Cooper \& Morgan, 2013; Hahn \& Lülfs, 2014; Merkl-Davies \& Brennan, 2007). En otros trabajos de contabilidad crítica se examina el tema con útil ilustración de la realidad. Por ejemplo, Denedo, Thomson \& Yonekura (2017) usan las contracuentas para reflejar la pérdida de biodiversidad en el Delta del Niger; Boiral (2016) expone la estrategia de neutralización frente a las denuncias de los stakeholders; Gray, Dillard \& Spence (2009) exhortan al desarrollo de cuentas sociales del aire, la tierra, el agua y otras categorías de experiencia humana y no humana; Jones $(1996,2003)$ reflexiona sobre el inventario natural y el rol de la contabilidad en la pérdida 
de biodiversidad; Jones, Jones, \& Solomon (2013) abordan los problemas subyacentes a la contabilidad de la biodiversidad, concepto que también ha sido tratado por otros investigadores (Atkins \& Maroun, 2018; Bebbington y Larrinaga, 2014; Bebbington \& Unerman, 2018; Cho et al., 2015; Cipullo, 2016; Cuckston, 2013, 2018; Khan, 2014; Lanka, Khadaroo, \& Böhm, 2017; Maroun \& Atkins, 2018; Turner, Ximenes, Penman et al., 2019).

Si se observa el panorama latinoamericano, y siguiendo a Ángel Maya (2003) para entender el problema ambiental es necesario comprender el ecosistema y los modelos culturales, lo que implica la interdisciplinariedad, con miras a construir una sociedad ambiental (Ángel Maya, 2013). De manera clara, Ángel Maya (1996), expresa que en la cumbre mundial de Río de Janeiro de 1972, la élite política no quiso examinar las causas de la crisis y prefirió soluciones exclusivamente tecnológicas, sin tocar las raíces económicas y sociales del problema ambiental.

De otra parte, mediante planteamientos críticos y asociados al desarrollo sostenible se ha sometido a examen la contabilidad de la sostenibilidad (Cooper, 1992; Gray, 1992, 1994; Lamberton, 2005). Podría insinuarse que lo expresado por Lamberton (2005), respecto de la naturaleza interdisciplinaria de la contabilidad de sostenibilidad con su cobertura tridimensional cobra hoy más vigencia, en tanto se requiere una mirada transdisciplinaria para auditar la efectividad de las acciones que intentan lograr la sostenibilidad. Es esta concurrencia de disciplinas y voces diferentes, incluidas las de los tradicionalmente ignorados, la que propicia la construcción de una contracontabilidad que pudiera considerarse alineada con un pensamiento ambiental alternativo al hegemónico.

Sin embargo, lograr esa visión heterodoxa no es nada fácil, incluso en presencia de contracuentas efectivas, porque el concepto de desarrollo sostenible y su expresión derivada 'sostenibilidad' han sido seriamente cuestionados (Estevan \& Naredo, 2009). Basta mirar la evolución de los indicadores de sus principales componentes para evidenciar sus carencias, omisiones e intenciones (Bebbington \& Larrinaga, 2014; Gray, 2002; Gray \& Milne, 2002). Entonces, se puede postular que una contabilidad del sistema capitalista es en la práctica una contabilidad del desarrollo insostenible, habida cuenta de los resultados poco efectivos, tal como lo evidencian las posturas emergentes de los principales investigadores críticos en los que se apoya este trabajo.

La contracontabilidad y expresiones asimilables corresponden a una manifestación académica que en pocos lustros ha logrado levantar una voz seria frente a la contabilidad tradicional -que sólo persigue alinearse con los intereses del capital-. Con base en Gallhofer, Haslam \& Monk (2006) y Gallofer \& Haslam (2003), se puede decir que tal concepto expresa un punto de vista contrario al hegemónico, mediante una crítica a las prácticas capitalistas. En una línea similar, Boiral (2013) argumenta que los informes corporativos camuflan problemas reales de desarrollo sostenible, por lo que dicha expresión permite su refutación por parte de stakeholders afectados, adquiriendo capacidad para desafiar los intereses opresivos y apoyar el cambio con miras a resultados emancipatorios (Denedo et al., 2017).

Se podría colegir que la contracontabilidad está del lado de los que no poseen capital en la empresa, configurando realmente una contabilidad civil, similar a la planteada por Spence (2009), por Vinnari \& Laine (2017), y de manera importante por Apóstol (2010), cuyo trabajo guarda importante analogía con el tema de este artículo, donde se evidencia que las voces de la sociedad civil constituyen el lado opuesto y contestatario de una realidad que va en vía contraria a los objetivos del desarrollo sostenible, así las corporaciones intenten desvirtuar estos hechos y denuncias a través de los informes de sostenibilidad (Boiral, 2016).

\section{Metodología}

Este trabajo se aborda desde una metodología crítica de investigación en contabilidad y asume que el lenguaje contable es un medio de poder social y represión, usado por la élite hegemónica corporativa, pero también reconoce su potencialidad para la emancipación (Chua, 2009; Ryan, Scapens, \& Theobald, 2004). Para ello, 
se acoge como estrategia el estudio de caso cualitativo. Este enfoque sigue el planteamiento de Ryan et al. (2004) puesto que no busca generalizar, sino que tiene un marcado interés en analizar un caso que fue elegido dada su importancia en la producción de carne, aunado al elevado nivel de cuestionamientos sociales por sus impactos.

Siguiendo los planteamientos de Alvesson \& Kärreman (2011), aplicados por estudios en este campo (Vinnari \& Laine, 2017), realizamos un análisis del discurso organizacional de JBS y lo contrastamos con fuentes externas. Desde esta perspectiva, el discurso permite aproximarse a una visión crítica de la realidad organizacional y es útil para el análisis empírico. A su vez, se plantea que el discurso por sí solo no puede dar respuesta de toda la realidad social, sino que debe ser analizado bajo el lente de un constructo teórico que permita ampliar la comprensión. En este caso, se estudiaron las prácticas que JBS relataba en sus informes y se contrapusieron con visiones alternativas, mediante el uso de datos tomados de diversos stakeholders, teniendo como foco de referencia la contracontabilidad. Específicamente, seleccionamos 11 documentos que promueven el discurso oficial de JBS y que comprenden tanto sus informes de sostenibilidad como los informes de sus auditores (BDO \& DNV GL) y 15 documentos que controvierten esta información y que provienen de diversas ONG y de medios alternativos correspondientes al período 2009 a 2019. En todos los casos se seleccionaron como unidades de análisis las piezas de información relacionada con la deforestación de la Amazonía brasileña y las posibles implicaciones de JBS en ello. Vale la pena aclarar que en el caso de las fuentes externas existen documentos completos dedicados a controvertir las posiciones oficiales de JBS, que presentan menos información al respecto y con mínimo detalle.

Adicionalmente, dado que la operación de JBS en Brasil se da en un escenario con múltiples actores sociedad civil, entidades del gobierno, participantes de otros países y la naturaleza- y con multiplicidad de interacciones y conflictos, usamos el concepto de "arena" en el caso JBS como una guía para entender el problema de la insostenibilidad de sus acciones, ver la figura 1 (Contrafatto et al., 2015; Georgakopulos \& Thomson, 2008; Renn, 1992; Thomson et al., 2010).

La metáfora de la arena sugiere procesos y relaciones que caracterizan una situación conflictiva, en la que existen relaciones de poder e influencia. Como lo sugieren Georgakopulos \& Thomson (2008) en el caso JBS participan diversos actores con unos roles definidos. Por ejemplo, los amplificadores son actores que observan las acciones en el contexto, las interpretan y las comunican. En este caso se incluyen medios de comunicación como The Guardian, Climate Home News, National Geographic, entre otros.

Los actores que tratan de influir en el panorama apoyando las acciones de JBS y que buscan demostrar que la compañía en cuestión cumple con regulaciones o acuerdos son en este caso los auditores independientes, las asociaciones en las cuales participa JBS para promover la ganadería responsable, los proveedores que participan en la deforestación, y los clientes que a pesar de conocer la responsabilidad de JBS en la deforestación continúan su relación comercial.

De otra parte, existen actores que tratan de exponer la responsabilidad de JBS en la deforestación y usan discursos alternativos para dar cuenta de ello. Se encuentran entre ellos las ONG que han elaborado informes con evidencias de las acciones de JBS que llevan a la insostenibilidad, tales como Greenpeace; también se incluyen las organizaciones de la sociedad civil que al verse afectadas han reclamado ser escuchados.

Las instituciones políticas son actores de poder que tienen acceso a la información y tienen influencia en las decisiones de la compañía y en la actuación de los stakeholders. En este caso, tanto el gobierno nacional como el gobierno regional son instituciones políticas que tienen responsabilidades e influencia frente a la deforestación. Finalmente, el caso presenta instituciones de vigilancia y control encargadas de hacer cumplir determinadas normas o de impartir sanciones por actuaciones inadecuadas. 


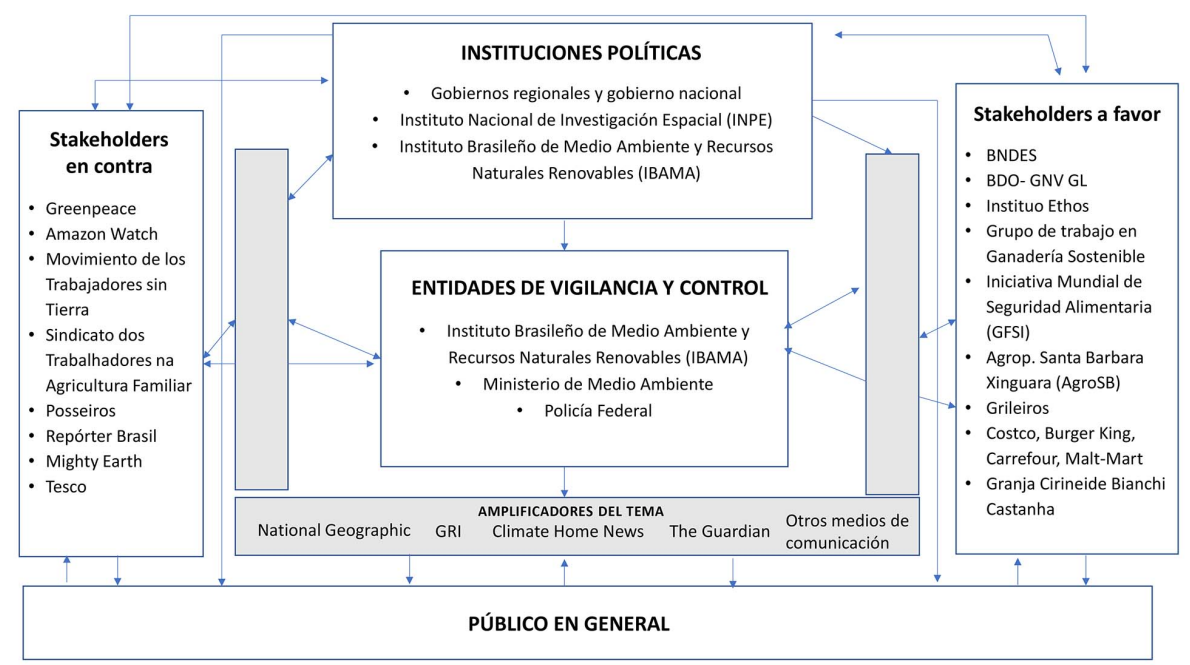

FIGURA 1

La arena de JBS en relación con la deforestación en Brasil Fuente: elaborado con base en Georgakopulos \& Thomson (2008).

En este caso, para construir la contracuenta partimos del informe emitido por Greenpeace en 2009 denominado Slaughtering the Amazon, haciendo un análisis de los argumentos esgrimidos por la ONG y los contrastamos con la información oficial contenida en los reportes de sostenibilidad de JBS S.A. desde 2011 (primer informe según Global Reporting Initiative - GRI) y en los informes de sus dos auditores independientes -BDO y DNV GL- desde 2013 a 2018. Con ello, encontramos los argumentos centrales de la posición oficial y los controvertimos, construyendo un relato alternativo desde los grupos de interés. Una síntesis del diseño metodológico se puede observar en la figura 2.

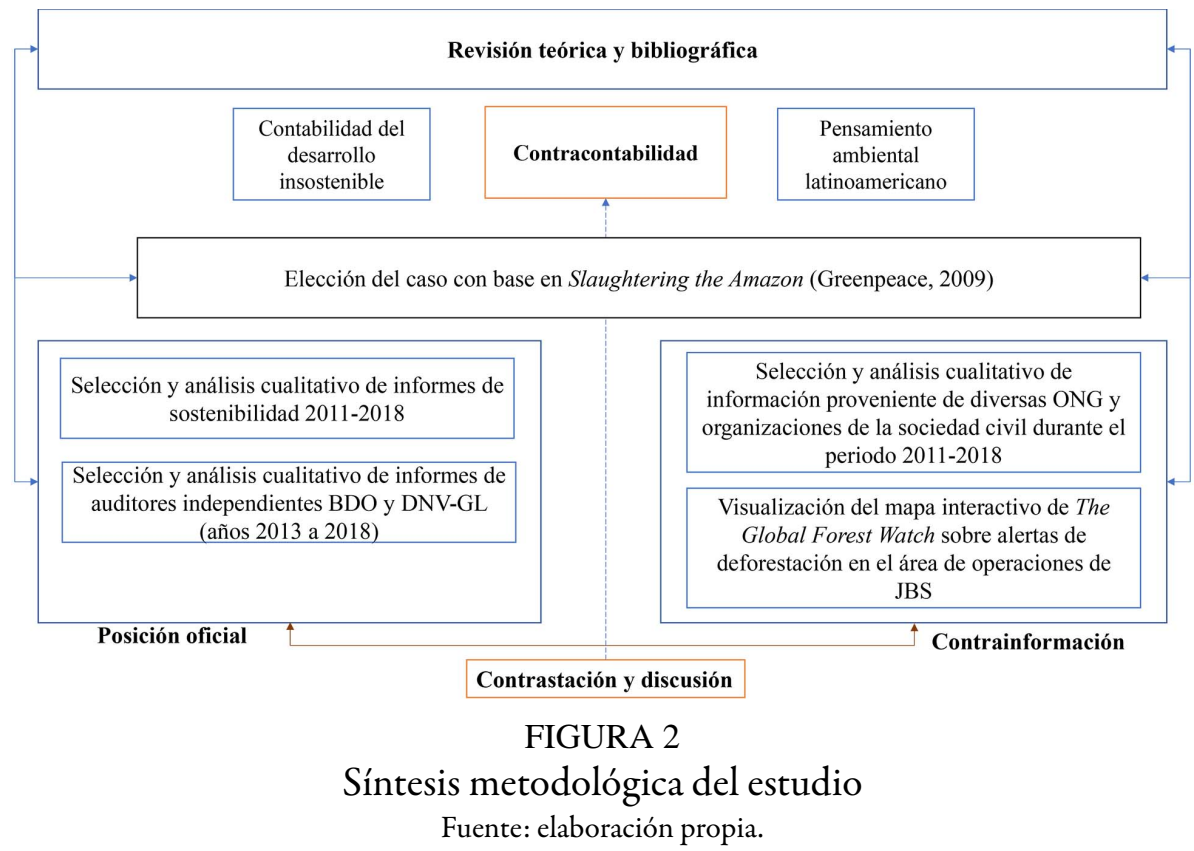




\section{El caso JBS y la deforestación en Brasil; análisis y discusión}

Esta sección presenta los resultados de sintetizar las diferentes posiciones de los principales actores involucrados en el caso JBS S.A., cuyo conjunto de voces dispares exige examinar sus discursos para construir una especie de cuenta holística emergente (Thomson et al., 2010).

Nuestro objetivo es atribuirle responsabilidad a esta compañía en la pérdida de biodiversidad por la deforestación en Brasil a partir de discursos contrahegemónicos ya que tanto la información oficial expuesta en los informes contables de JBS como los informes de los auditores independientes muestran la visión organizacional, normalizan el despojo de la naturaleza y trasladan la responsabilidad. Así, a partir de contrainformación se dilucida cómo las dinámicas de la contabilidad social y ambiental de los informes de sostenibilidad no son más que simulacros que maquillan las acciones de las grandes empresas que ocasionan, favorecen o perpetúan el deterioro ambiental (Boiral, 2013).

\section{Perfil de JBS}

JBS S.A. es una compañía brasileña perteneciente al sector de procesamiento de carnes, reconocida como uno de los líderes mundiales en la industria y con presencia en 15 países entre los que se encuentran Estados Unidos, Canadá, México y Francia (JBS S.A., 2019b; Reuters, 2020).

En el año 2007 JBS ingresó a la Bolsa de Valores de São Paulo y en los años siguientes realizó importantes adquisiciones en Estados Unidos, Australia y Argentina. Actualmente la compañía cuenta con oficinas y plantas en cinco continentes y abarca tres segmentos de negocio: carne de res, pollo, cerdo y diversos subproductos. Opera las marcas Pride, Friboi, Seara, Pilgrim's y Plumrose, entre otras (JBS S.A., 2019a; Reuters, 2020). De acuerdo con su informe de sostenibilidad de 2018 el 40,64\% de JBS es controlado por J\&F Investimentos S\&A e Formosa; el 21,32\% es propiedad de BNDES Participações S.A. y el 35,6\% es propiedad de accionistas minoritarios (JBS S.A., 2019a). En 2019, Amazon Watch reveló los principales accionistas institucionales europeos y norteamericanos de JBS, como se observa en la tabla 1.

TABLA 1

Principales inversores institucionales de JBS provenientes de Europa y Norteamérica

\begin{tabular}{|c|l|l|r|r|r|}
\hline No & \multicolumn{1}{|c|}{ Inversor } & \multicolumn{1}{|c|}{ País } & $\begin{array}{c}\text { Cantidad de } \\
\text { acciones }\end{array}$ & $\begin{array}{c}\text { \% de } \\
\text { acciones }\end{array}$ & $\begin{array}{c}\text { Valor } \\
\text { (Millones } \\
\text { U\$) }\end{array}$ \\
\hline 1 & Capital Group & Estados Unidos & 230.458 .741 & 8,4 & 819 \\
\hline 2 & BlackRock & Estados Unidos & 56.426 .693 & 2,1 & 217 \\
\hline 3 & Fidelity Investments & Estados Unidos & 43.880 .955 & 1,6 & 157 \\
\hline 4 & Vanguard & Estados Unidos & 35.198 .267 & 1,3 & 126 \\
\hline 5 & Dimensional Fund Advisors & Estados Unidos & 30.396 .002 & 1,1 & 109 \\
\hline 6 & APG Group & Países Bajos & 15.096 .283 & 0,6 & 36 \\
\hline 7 & GMO & Estados Unidos & 11.678 .100 & 0,4 & 36 \\
\hline 8 & Caisse de dépôt et placement du Québec & Canadán & 10.715 .507 & 0,4 & 32 \\
\hline 9 & Crédit Agricole & Francia & 10.370 .572 & 0,4 & 37 \\
\hline 10 & Causeway Capital Holdings & Estados Unidos & 8.761 .200 & 0,3 & 26 \\
\hline 11 & BrightSphere Investment Group & Reino Unido & 8.232 .564 & 0,3 & 29 \\
\hline 12 & Prudential (UK) & Reino Unido & 7.547 .339 & 0,3 & 23 \\
\hline 13 & McKinley Capital Management & Estados Unidos & 5.968 .700 & 0,2 & 21 \\
\hline 14 & Charles Schwab & Estados Unidos & 4.649 .463 & 0,2 & 19 \\
\hline 15 & T. Rowe Price & Estados Unidos & 4.414 .900 & 0,2 & 13 \\
\hline 16 & Fidelity International & Bermuda & 3.336 .174 & 0,1 & 12 \\
\hline 17 & Florida State Board of Administration & Estados Unidos & 2.966 .475 & 0,1 & 8 \\
\hline 18 & Deutsche Bank & Alemania & 2.888 .972 & 0,1 & 10 \\
\hline 19 & Research Affiliates & Estados Unidos & 2.701 .900 & 0,1 & 8 \\
\hline 20 & State Street & Estados Unidos & 2.507 .330 & 0,1 & 9 \\
\hline & & & & & \\
\hline
\end{tabular}

Fuente: Amazon Watch (2019).

Dada su importancia mundial, JBS pertenece a diversas asociaciones en pro de la sostenibilidad entre las que se encuentran La Mesa Redonda Mundial para Carne de Res Sostenible (GRSB por sus siglas en inglés), la iniciativa en agricultura sostenible, el Instituto Ethos en Brasil y el Grupo de Trabajo en Ganadería Sostenible 
de Brasil, entre otras (JBS S.A., 2019a). Además, la información del Global Reporting Initiative sugiere que JBS ha emitido reportes de sostenibilidad desde 2011 (GRI, 2019).

Debido a la naturaleza del negocio, JBS depende de una gran cantidad de proveedores de diversas características en todo el mundo, por lo que asegura cumplir con los más altos estándares de evaluación, que incluyen un programa de auditoría anual basado en los criterios de la Iniciativa Mundial de Seguridad Alimentaria (JBS S.A., 2019a).

En esta línea, la compañía asegura que su enfoque de sostenibilidad promueve la transparencia y la ética, lo que se traduce en un acercamiento responsable con sus grupos de interés y con el ambiente (JBS S.A., 2019a). Paradójicamente, en los últimos años JBS ha estado involucrada en escándalos por corrupción en Brasil, por sobornos a tres presidentes y a más de 1.800 funcionarios públicos (Mongabay Latam, 2019) y por vender carne en condiciones no aptas para el consumo humano (BBC, 2017).

Como parte de sus políticas ambientales esta compañía asegura que en Brasil tiene un sistema de monitoreo social y ambiental para verificar si sus proveedores cumplen con su política. Este sistema aparentemente monitorea problemas como la deforestación de bosques en tierras indígenas, en áreas de conservación ambiental o áreas embargadas por el Instituto Brasileño de Medio Ambiente y Recursos Naturales (IBAMA) (JBS S.A., 2019a).

Anualmente JBS somete su sistema de monitoreo a un auditor externo que elabora un informe de cumplimiento y evaluación sobre el compromiso público de ganadería, fruto del acuerdo sostenido con Greenpeace en 2009 para eliminar de sus listas de proveedores a aquellas empresas frigoríficas que estuvieran involucradas en la deforestación de la selva amazónica. De acuerdo con sus reportes, JBS ha cumplido en un alto porcentaje con dicho acuerdo, mostrándose como una organización transparente y responsable (DNV GL, 2017b; JBS S.A., 2017, 2019a).

\section{JBS y la deforestación en Brasil}

Brasil presenta una paradoja ambiental: por un lado, en su territorio se encuentra la extensión más grande del mundo en bosque tropical terrestre (Greenpeace, 2020). Por otro, es uno de los líderes globales en producción y exportación de carne y soya, actividades reconocidas como las principales causantes de la deforestación de bosques tropicales (Gibbs, Munger, L'Roe et al., 2016). Este problema ha aumentado de forma creciente en Brasil en los últimos años debido a la ganadería extensiva, algunas veces ilegal (Greenpeace, 2020).

En 2009 la ONG Greenpeace emitió el reporte Slaughtering the Amazon en el cual señaló que Brasil ocupaba el cuarto lugar en emisión de gases de efecto invernadero, producto de la deforestación del bosque tropical, impactando la biodiversidad y contribuyendo al calentamiento global. En dicho informe se responsabilizó directamente al sector ganadero de ser el principal causante de la deforestación y se acusó al gobierno brasilero de favorecer este comportamiento a través de préstamos, inversiones y controles poco rigurosos (Greenpeace, 2009c).

Además de ello, Greenpeace señalaba que hasta 2009 Brasil era el país con mayor exportación de carne en el mundo, situación que se mantiene hasta la actualidad, de acuerdo con datos del departamento de agricultura de Estados Unidos, como se observa en la figura 3. Asimismo, la FAO confirmó que Brasil es el país con el inventario de ganado más grande en el mundo con 214.899.796, equivalentes al 14,41\% del total mundial a 2017 (FAOSTAT, 2017). 


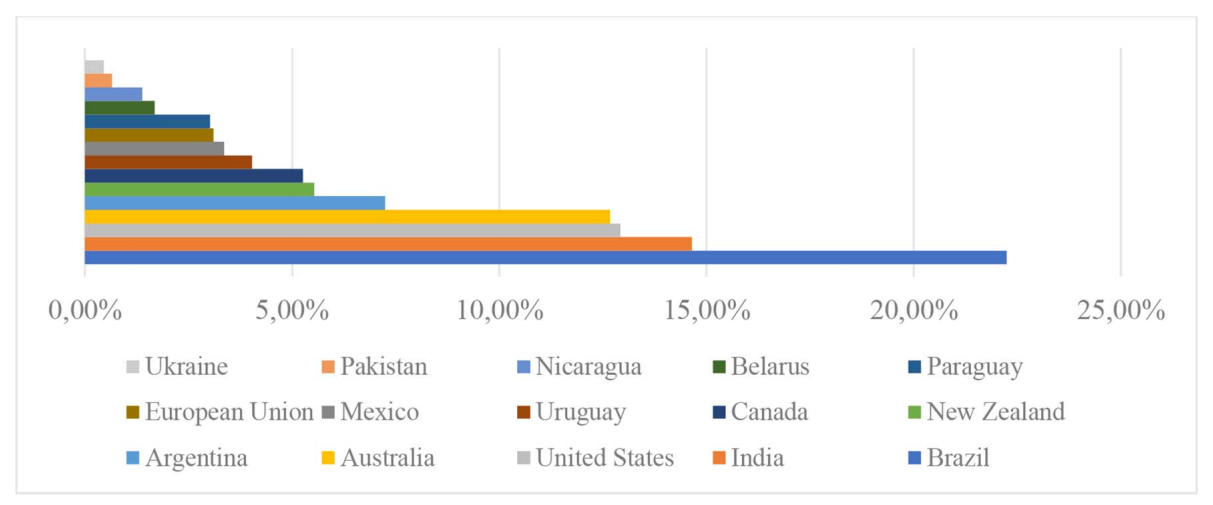

FIGURA 3

Países con mayores porcentajes de exportación de carne en el mundo Fuente: USDA (2020).

Adicionalmente, entre 2006 y 2009 Greenpeace realizó 39 investigaciones encubiertas a tres de las compañías más grandes del comercio cárnico en Brasil y a nivel global: JBS S.A., Bertin y Marfrig. A pesar de que las tres empresas aseguraban cumplir con estándares de conservación y no participar en la deforestación del Amazonas, estas investigaciones identificaron que muchos de los proveedores regulares de estas empresas deforestaban la Amazonía y que tal actividad criminal era "lavada" a través de la cadena de suministro. En el caso específico de JBS los hallazgos sugieren que esta organización exportaba proteína animal de granjas deforestadoras y proveía a grandes cadenas como Carrefour y WalMart (Greenpeace, 2009c). En su investigación, la ONG utilizó imágenes satelitales, datos del gobierno, documentos confidenciales de las compañías, información de personas vinculadas a las empresas en cuestión, e información comercial mundial clasificada (Greenpeace, 2009c).

La tabla 2 muestra los datos de las granjas identificadas por Greenpeace en Matto Grosso que se encontraban deforestadas y que proveían a JBS en 2008. Esta información no se encuentra en ninguno de los informes de sostenibilidad de la empresa, ni se relaciona en algún informe de sus auditores.

TABLA 2

Granjas que proveían ganado a JBS en Matto Grosso en 2008

\begin{tabular}{|c|c|c|c|c|c|c|}
\hline $\mathrm{N}^{\circ}$ & $\begin{array}{l}\text { Nombre de } \\
\text { la granja }\end{array}$ & $\begin{array}{l}\text { Dueño de la } \\
\text { granja }\end{array}$ & $\begin{array}{l}\text { Localización en } \\
\text { Matto Grosso }\end{array}$ & $\begin{array}{c}\text { Tamaño } \\
\text { (Has) }\end{array}$ & $\begin{array}{l}\text { \% de defo- } \\
\text { restación en } \\
\text { la granja }\end{array}$ & $\begin{array}{r}\text { Cabezas de } \\
\text { ganado junio- } \\
\text { agosto 2008 }\end{array}$ \\
\hline 1 & Australia & $\begin{array}{l}\text { Braulino Basílio } \\
\text { Maia Filho }\end{array}$ & $\begin{array}{l}\text { Vila Bela da } \\
\text { Santissima } \\
\text { Trindade }\end{array}$ & 2.448 & $90-100$ & 1.620 \\
\hline 2 & $\begin{array}{l}\text { Brinco de } \\
\text { Ouro }\end{array}$ & $\begin{array}{l}\text { Sidney Gasques } \\
\text { Bordoni }\end{array}$ & $\begin{array}{l}\text { Vila Bela da } \\
\text { Santíssima } \\
\text { Trindade }\end{array}$ & 2.741 & $50-60$ & 2.056 \\
\hline 3 & Eunice & $\begin{array}{l}\text { Donato Lemos } \\
\text { Berado }\end{array}$ & $\begin{array}{l}\text { Vila Bela da } \\
\text { Santíssima } \\
\text { Trindade }\end{array}$ & 7.570 & $50-60$ & 3.605 \\
\hline 4 & GM & $\begin{array}{l}\text { Manoel Jorge } \\
\text { Ribeiro }\end{array}$ & Lambari d'Oeste & 757 & $90-100$ & 72 \\
\hline 5 & Jacutinga & $\begin{array}{l}\text { Fernanda } \\
\text { Aufiero }\end{array}$ & $\begin{array}{l}\text { Figueriópolis } \\
\text { d'Oeste }\end{array}$ & 2.532 & $90-100$ & 1.377 \\
\hline 6 & Paturi & $\begin{array}{l}\text { José Reis } \\
\text { Pereira Filho }\end{array}$ & $\begin{array}{l}\text { Vila Bela da } \\
\text { Santíssima } \\
\text { Trindade }\end{array}$ & 1.731 & $90-100$ & 3.410 \\
\hline 7 & $\begin{array}{l}\text { Santa Amália } \\
\text { do Tangará }\end{array}$ & $\begin{array}{l}\text { Renato } \\
\text { Junqueira } \\
\text { Meirelles }\end{array}$ & $\begin{array}{l}\text { Tangará da } \\
\text { Serra }\end{array}$ & 8.466 & $90-100$ & 180 \\
\hline 8 & $\begin{array}{l}\text { Santa Maria } \\
\text { do Guaporé }\end{array}$ & $\begin{array}{l}\text { Sidney Gasques } \\
\text { Bordoni }\end{array}$ & $\begin{array}{l}\text { Vila Bela da } \\
\text { Santíssima } \\
\text { Trindade }\end{array}$ & 3.204 & $60-70$ & 636 \\
\hline 9 & $\begin{array}{l}\text { Agropecuaria } \\
\text { Lima }\end{array}$ & $\begin{array}{l}\text { Antônio } \\
\text { Roberto de } \\
\text { Lima }\end{array}$ & Querência & 2.982 & $80-90$ & 195 \\
\hline 10 & Chapéu I \& I & $\begin{array}{l}\text { Milton Vilela de } \\
\text { Carvalho }\end{array}$ & $\begin{array}{l}\text { Bom Jesus do } \\
\text { Araguaia / } \\
\text { Ribeirao } \\
\text { Cascalheira }\end{array}$ & 17.091 & $80-90$ & 2.174 \\
\hline 11 & $\begin{array}{l}\text { Gleba } \\
\text { Ribeirão }\end{array}$ & Luciana Selmi & $\begin{array}{l}\text { Ribeirão } \\
\text { Cascalheira }\end{array}$ & 1.694 & $40-50$ & 442 \\
\hline 12 & Roncador & $\begin{array}{l}\text { Agropecuária } \\
\text { Roncador }\end{array}$ & Querência & 149.095 & $50-60$ & 15.708 \\
\hline 13 & Roxo & $\begin{array}{l}\text { Adecréscio } \\
\text { Pedro de Aguiar }\end{array}$ & Querência & 6.140 & $60-70$ & 168 \\
\hline
\end{tabular}

Fuente: Greenpeace (2009a). 
Un mes después de publicado el informe, las compañías cuestionadas (entre ellas JBS) se comprometieron a no comprar ganado a quienes deforestaran y firmaron un término de referencia denominado 'Criterios mínimos para las operaciones de ganado a escala industrial en la bioma de la Amazonía Brasileña’ en el que se comprometían a auditar por un tercero sus compras de ganado y a publicar sus resultados contra la deforestación (Greenpeace, 2009b).

En 2011, JBS aseguró en su primer informe de sostenibilidad que adoptó criterios ambientales para seleccionar sus proveedores usando una lista de chequeo que verificaba el cumplimiento de asuntos de la legislación brasileña como el no uso de áreas embargadas por deforestación ilegal, también se refirió al compromiso público contra la deforestación ilegal y, como parte de este acuerdo resaltó la implementación del sistema de rastreo satelital que identifica a los proveedores y su situación (JBS S.A., 2012).

A pesar de lo acordado, en 2012 Greenpeace reportó que JBS no había cumplido nada del compromiso pactado, mientras esta empresa negaba el incumplimiento y tomaba acciones legales contra la ONG. Sin embargo, luego de un diálogo entre ambas organizaciones se retomaron los compromisos firmados en 2009. Tal hecho se registró en el informe de sostenibilidad de JBS de 2012 (JBS S.A., 2013) y Greenpeace presentó un reporte en el que señaló que "JBS finalmente ha publicado una auditoría de sus sistemas de suministro y un plan de trabajo para garantizar que cumpla con los compromisos pendientes dentro del Acuerdo"(Greenpeace, 2012).

Los informes de auditoría independientes de BDO (2013 y 2014) señalaron que JBS estaba cumpliendo con el desarrollo de un sistema de monitoreo de proveedores desde 2010 en dos sentidos: una comparación entre las listas de proveedores y las listas de granjas embargadas por el IBAMA para bloquear automáticamente a aquellos que estuvieran en áreas embargadas; y un sistema de rastreo satelital usando geo-monitoreo a través de una herramienta denominada 'Agrotools', la cual evalúa si los proveedores se encuentran dentro del área de deforestación de acuerdo con mapas oficiales del Instituto Nacional de Pesquisas Espaciais (INPE).

Las auditorías fueron realizadas siguiendo la norma de procedimientos acordados para estados contables, aprobada por resolución 1277/2010; se desarrollaron con base en inspección documental, entrevistas a empleados y simulaciones, y las pruebas se realizaron con muestreo del $15 \%$ de las transacciones para 2013 y 10\% para 2014. En ambos años la opinión del auditor fue favorable en tanto no se encontraron incumplimientos en el ejercicio de comparación de listas entre JBS y el IBAMA. En cuanto a la georreferenciación, ambos informes identifican casos que no cumplen con el acuerdo, en un porcentaje muy bajo.

En 2015 Greenpeace reconoció el avance de JBS en el cumplimiento de los acuerdos, lo que coincidió con el informe de auditoría emitido por BDO que señaló que, con base en una muestra de $10 \%$ de las transacciones, se cumplió en un 99,97\% con el acuerdo firmado (BDO, 2016; Greenpeace, 2015). En el mismo año la ONG Repórter Brasil acusó a JBS de comprar cientos de reses a la familia Castanha, señalada por la Policía Federal de ser "la mayor deforestadora de la Amazonía de todos los tiempos". Después de tal acusación, JBS bloqueó la compra de ganado a dicho proveedor (Repórter Brasil, 2015).

El estudio de Gibbs et al. (2016) concluyó que después de firmado el acuerdo entre JBS y Greenpeace se dio una reducción significativa en la contratación de granjas que deforestaran ilegalmente (Climate Home News, 2017). No obstante, en 2017 el IBAMA desarrolló la operación "carne fría" (Cold Meat) y embargó dos plantas empacadoras de carne a JBS por encontrar que ésta había incumplido el compromiso con Greenpeace y la multó por más de 24 millones de reales. Con ello, Greenpeace suspendió las negociaciones con JBS (Greenpeace, 2017). Los informes independientes de auditoría, emitidos por DNV GL para 2016 y 2017 habían concluido un cumplimiento de los acuerdos en el 99,9\% de las compras (DNV GL, 2017a, 2018).

De acuerdo con información de Climate Home News (2017), el ganado de granjas embargadas había sido transportado a otros lugares para ocultar su origen, con lo que quedó expuesto que el sistema de monitoreo implementado rastreaba las propiedades pero no las reses individualmente consideradas (Fearnside, 2017), y que JBS no ejercía ningún tipo de control o auditoría sobre los proveedores indirectos, haciendo invisible 
parte de la cadena de suministro (The Guardian, 2019). Más recientemente, Amazon Watch publicó un informe en el que evidenció que la Agropecuária Santa Barbara Xinguara (AgroSB) y la Agropecuária Rio da Areia LTDA, multadas en 2017 y 2018 por deforestación ilegal eran dos de los principales proveedores de ganado a JBS (Amazon Watch, 2019).

El Atlas de Justicia Medioambiental señala además que JBS ha comprado ganado a granjas que han sido despojadas por los denominados 'grileiros' o acaparadores -agricultores y ganaderos que afirmaban poseer o comprar tierras públicas con documentos falsificados- y que son responsables de la deforestación indiscriminada en regiones como Matto Grosso, afectando gravemente a otros actores vulnerables, generalmente trabajadores rurales (EJAtlas, 2018).

En 2019 la selva amazónica brasileña se vio gravemente afectada por miles de incendios forestales provocados. La deforestación derivada de ello generó impactos dramáticos en la riqueza de especies debido a que esta región alberga el 10\% de los animales que habitan la tierra (National Geographic, 2019). Estudios anteriores determinaron que la deforestación produce una pérdida de entre 30 y $40 \%$ de la riqueza de las especies (Decaëns et al., 2018). Además, los impactos para la fauna y flora se presentan tanto inmediatamente como en el largo plazo, teniendo en cuenta que los bosques tropicales son necesarios para mantener el equilibrio ecosistémico (UNEP - UN Environment Programme, 2019). Con los incendios provocados y la deforestación, algunas especies se ven desplazadas y otras mueren por la inhalación de humo o producto de las quemaduras.

La figura 4 muestra el aumento en las alertas de deforestación en Brasil entre 2015 y 2019. El primer recuadro muestra las alertas a diciembre de 2017 y el segundo recuadro muestra las alertas a diciembre de 2019.

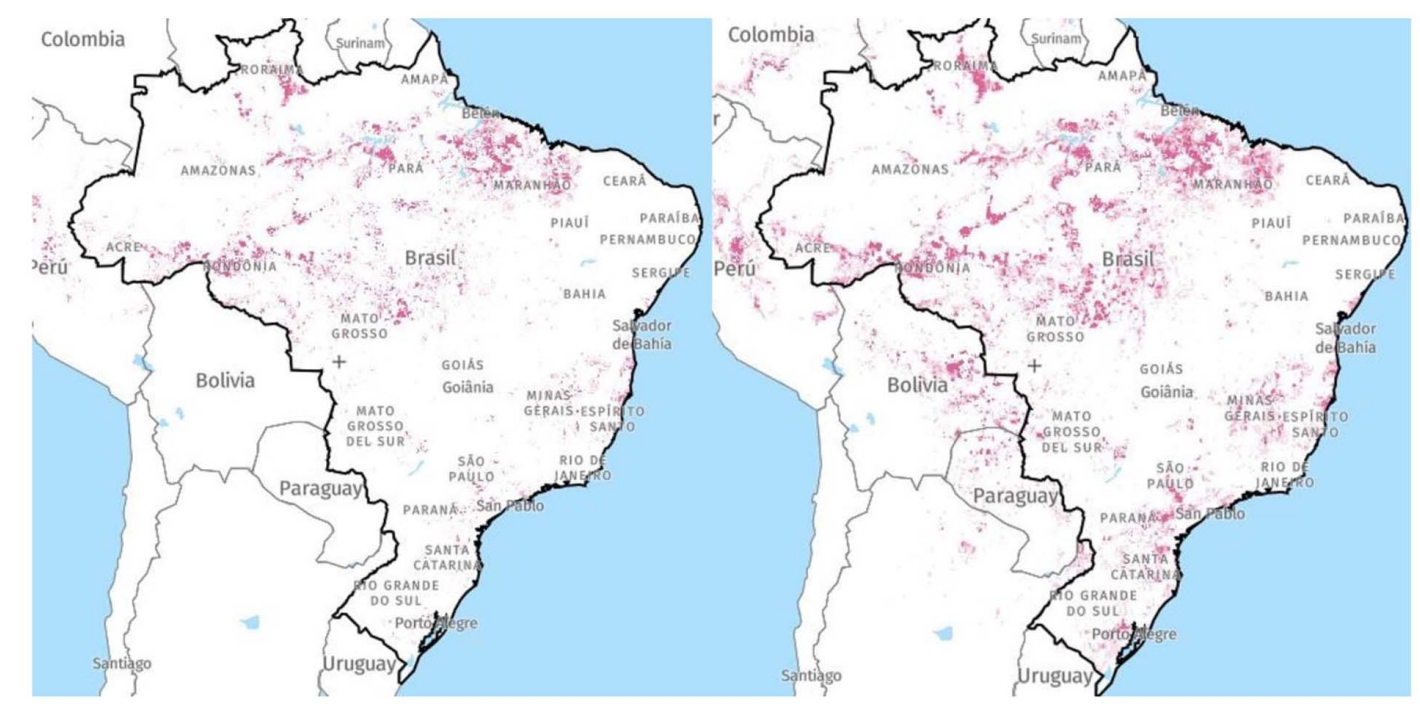

FIGURA 4

Alertas de deforestación en Brasil a diciembre 2017 (izquierda) y a diciembre 2019 (derecha) Fuente: Global Forest Watch (2020).

En 2019 Mighty Earth publicó un informe titulado The Companies Behind the Burning of the Amazon en el que sugirió que la ganadería a gran escala representó un incentivo perverso para los incendios de la Amazonía brasileña. Sus análisis evidenciaron que los mataderos de JBS se encontraban muy cerca de los incendios en la Amazonía, como se observa en la figura 5, lo que muestra que después de diez años JBS sigue siendo uno de los responsables por la deforestación en el Brasil. Esto contradice de manera clara el discurso oficial de la empresa que alude constantemente a su compromiso ético y ambiental. 


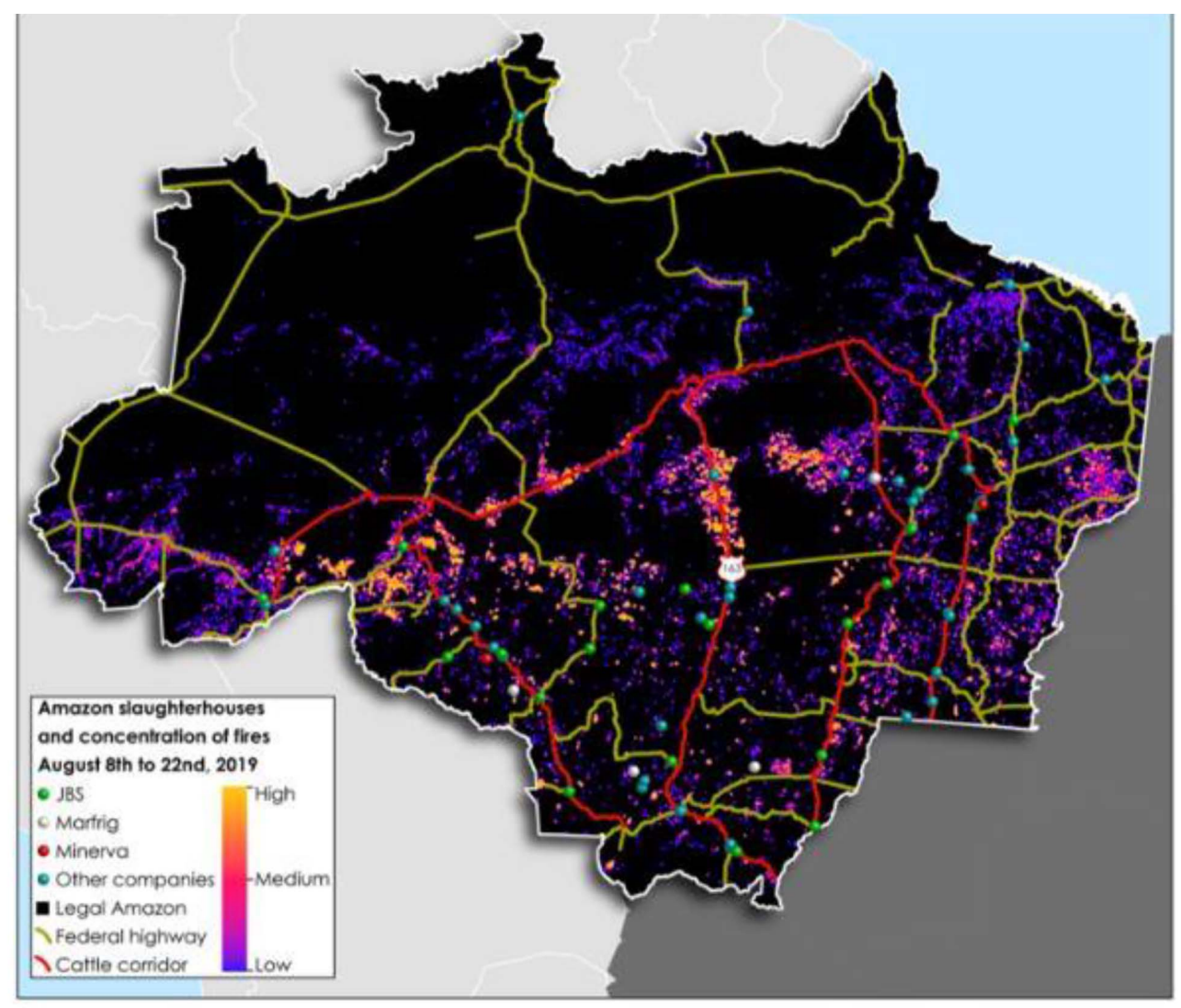

FIGURA 5

Mataderos en el Amazonas y concentración de incendios (agosto 8-22, 2019) Fuente: Mighty Earth (2019)

En la actualidad, compañías como Costco, Burger King, Carrefour y Walt-Mart siguen realizando negocios con JBS (Mighty Earth, 2019), mientras que algunos de sus antiguos clientes, como Tesco, han decidido terminar la relación comercial luego de los escándalos por deforestación (The Guardian, 2012). Recientemente, JBS firmó un acuerdo comercial con el grupo WH para exportar carne a china, en más de 60.000 puntos de venta (Euromeatnews.com, 2020), y un estudio conjunto entre The Guardian, The Bureau of Investigative Journalism y Repórter Brasil (2020) hizo pública una serie de imágenes posteadas por un conductor de JBS en las que se confirma aún el traslado de ganado desde granjas deforestadoras.

Teniendo en cuenta lo anterior, una síntesis de las cuentas oficiales de JBS y las contracuentas presentadas por actores de la sociedad civil se observa en la tabla 3. 
TABLA 3

Cuentas y Contracuentas del caso JBS

\begin{tabular}{|c|c|}
\hline Cuentas JBS & Contracuentas \\
\hline $\begin{array}{l}\text { JBS promueve la transparencia y la ética, traducidos en } \\
\text { un acercamiento responsable con sus grupos de interés y } \\
\text { el ambiente. Prioriza la salud y la seguridad de } \\
\text { miembros de la compañía, bienestar animal, integridad } \\
\text { del producto, la gestión del agua y el cambio climático } \\
\text { (JBS S.A., 2019a). }\end{array}$ & $\begin{array}{l}\text { JBS ha estado involucrada en escándalos por corrupción en } \\
\text { Brasil, por sobornos a tres presidentes y a más de } 1.800 \\
\text { funcionarios públicos (Mongabay Latam, 2019) y por vender } \\
\text { carne en condiciones no aptas para el consumo humano (BBC, } \\
\text { 2017). }\end{array}$ \\
\hline $\begin{array}{l}\text { JBS tiene un sistema de monitoreo social y ambiental } \\
\text { robusto para verificar si los proveedores de ganado } \\
\text { cumplen con los estándares de su política de compra de } \\
\text { materia prima. El sistema monitorea la deforestación de } \\
\text { bosques nativos en tierras indígenas, en áreas de } \\
\text { conservación ambiental o áreas embargadas por el } \\
\text { Instituto Brasileño de Medio Ambiente y Recursos } \\
\text { Naturales (IBAMA) (JBS S.A., 2019a). }\end{array}$ & $\begin{array}{l}\text { Science (2019) señala que las imágenes de satélite Landsat del } \\
\text { Programa de Monitoreo de Deforestación de la Amazonia por } \\
\text { Satélite corroboran el incremento de las tasas de deforestación } \\
\text { en } 2019 \text {. Greenpeace }(2009 \text { c) emitió un reporte sobre } \\
\text { deforestación del bosque tropical y responsabilizó } \\
\text { directamente al sector ganadero de ser el principal causante de } \\
\text { la deforestación global, entre ellos a JBS. }\end{array}$ \\
\hline $\begin{array}{l}\text { Tres de las compañías más grandes del comercio } \\
\text { cárnico en Brasil y a nivel global: JBS S.A., Bertin y } \\
\text { Marfrig aseguraban cumplir con estándares de } \\
\text { conservación y no participar en la deforestación del } \\
\text { Amazonas. }\end{array}$ & $\begin{array}{l}\text { Greenpeace (2009c) identificó que muchos proveedores de } \\
\text { JBS deforestaban ilegalmente y que tal actividad criminal era } \\
\text { "lavada" a través de la cadena de suministro. JBS proveía a } \\
\text { grandes cadenas como Carrefour proteína animal proveniente } \\
\text { de granjas que deforestaban ilegalmente. El Atlas de Justicia } \\
\text { Medioambiental señala que JBS compró ganado a granjas } \\
\text { despojadas por los 'grileiros' o acaparadores (EJAtlas, 2018). }\end{array}$ \\
\hline $\begin{array}{l}\text { JBS S.A. (2012) adoptó criterios ambientales para } \\
\text { seleccionar sus proveedores usando una lista de chequeo } \\
\text { del cumplimiento de asuntos de la legislación brasilera e } \\
\text { implementó el sistema de rastreo satelital que permite } \\
\text { identificar a los proveedores y su situación. }\end{array}$ & $\begin{array}{l}\text { En } 2012 \text { Greenpeace reportó que JBS no había cumplido nada } \\
\text { del compromiso pactado. }\end{array}$ \\
\hline $\begin{array}{l}\text { JBS emprende acciones legales contra Greenpeace por } \\
\text { asegurar que no había cumplido el acuerdo. Luego de un } \\
\text { diálogo entre ambas organizaciones se retomaron los } \\
\text { compromisos firmados (JBS S.A., 2013). }\end{array}$ & $\begin{array}{l}\text { Greenpeace señaló que en } 2012 \text { luego del diálogo, JBS } \\
\text { finalmente publicó el resultado de una auditoría de sus } \\
\text { sistemas de suministro y un plan de trabajo para garantizar se } \\
\text { cumplan los acuerdos (Greenpeace, 2012). }\end{array}$ \\
\hline $\begin{array}{l}\text { BDO, el auditor independiente de JBS señaló que JBS } \\
\text { cumplió con los acuerdos en } 2013 \text { y } 2014 \text {, luego de } \\
\text { verificar el uso del sistema Agrotools y realizar un } \\
\text { muestreo de transacciones con proveedores } \\
\text { (seleccionando } 15 \% \text { de transacciones en } 2013 \text { y } 10 \% \text { en } \\
\text { 2014). Para } 2015 \text {, BDO (2016) expresó en su informe de } \\
\text { auditoría que JBS cumplió el acuerdo en } 99,97 \% \text {. }\end{array}$ & $\begin{array}{l}\text { En 2015, Greenpeace, reconoció el avance de JBS en el } \\
\text { cumplimiento de los acuerdos. Greenpeace, 2015). Pero, la } \\
\text { ONG Repórter Brasil acusó a JBS de comprar cientos de reses } \\
\text { a la familia Castanha, señalada de ser "la mayor deforestadora } \\
\text { de la Amazonía de todos los tiempos". Después de tal } \\
\text { acusación, JBS bloqueó la compra de ganado a dicho } \\
\text { proveedor (Repórter Brasil, 2015). }\end{array}$ \\
\hline $\begin{array}{l}\text { En } 2016 \text { JBS cambia de auditor y contrata a DNV GL, } \\
\text { quien para } 2016 \text { y } 2017 \text { concluyó un cumplimiento de } \\
\text { los acuerdos en el } 99.9 \% \text { de las compras (DNV GL, } \\
2017 \text { a } 2018 \text { ). }\end{array}$ & $\begin{array}{l}\text { Después de firmado el acuerdo entre JBS y Greenpeace se dio } \\
\text { una reducción significativa en la contratación de granjas que } \\
\text { deforestaran ilegalmente (Climate Home News, 2017). La } \\
\text { operación "carne fría" del IBAMA encontró que la compañía } \\
\text { había incumplido el compromiso con Greenpeace y la multó } \\
\text { por más de } 24 \text { millones de reales. Greenpeace suspendió las } \\
\text { negociaciones con JBS (Greenpeace, 2017). }\end{array}$ \\
\hline \multirow[t]{2}{*}{$\begin{array}{l}\text { JBS negó las acusaciones del IBAMA, aunque su } \\
\text { auditor DNV GL explicó que JBS no tiene aún control } \\
\text { de los proveedores indirectos. }\end{array}$} & $\begin{array}{l}\text { E1 IBAMA encontró que el ganado de granjas embargadas } \\
\text { había sido transportado a granjas no embargadas para ocultar } \\
\text { su origen (Fearnside, 2017). Amazon Watch (2019) evidenció } \\
\text { que AgroSB y la Agropecuária Rio da Areia LTDA, multadas } \\
\text { por deforestación ilegal eran dos de los principales } \\
\text { proveedores de ganado de JBS. }\end{array}$ \\
\hline & $\begin{array}{l}\text { En } 2019 \text { Mighty Earth publicó un informe en el que evidenció } \\
\text { que los mataderos de JBS se encontraban muy cerca de los } \\
\text { incendios en la Amazonía (Mighty Earth, 2019). }\end{array}$ \\
\hline $\begin{array}{l}\text { Costco, Burger King y Carrefour siguen haciendo } \\
\text { negocios con JBS (Mighty Earth, 2019). En } 2020 \text { el } \\
\text { grupo WH firmó un acuerdo con JBS para exportar } \\
\text { carne a china (Euromeatnews.com, 2020). }\end{array}$ & $\begin{array}{l}\text { Algunos clientes, como Tesco, han decidido terminar la } \\
\text { relación comercial luego de los escándalos por deforestación } \\
\text { (The Guardian, 2012). }\end{array}$ \\
\hline
\end{tabular}

Fuente: elaboración propia.

El análisis de los documentos seleccionados nos permitió generar un sumario de los temas más relevantes que se encuentran en el discurso oficial de JBS versus los que se encuentran en las fuentes externas. Dicho resumen se presenta en las figuras 6 y 7 , en las cuales se vislumbra claramente que el discurso contable oficial de JBS invisibiliza su responsabilidad y omite gran parte de los hechos. Adicionalmente, en las tablas A1 y A2 del anexo detallamos la distribución de temas relevantes por actor involucrado en la situación conflictiva. 


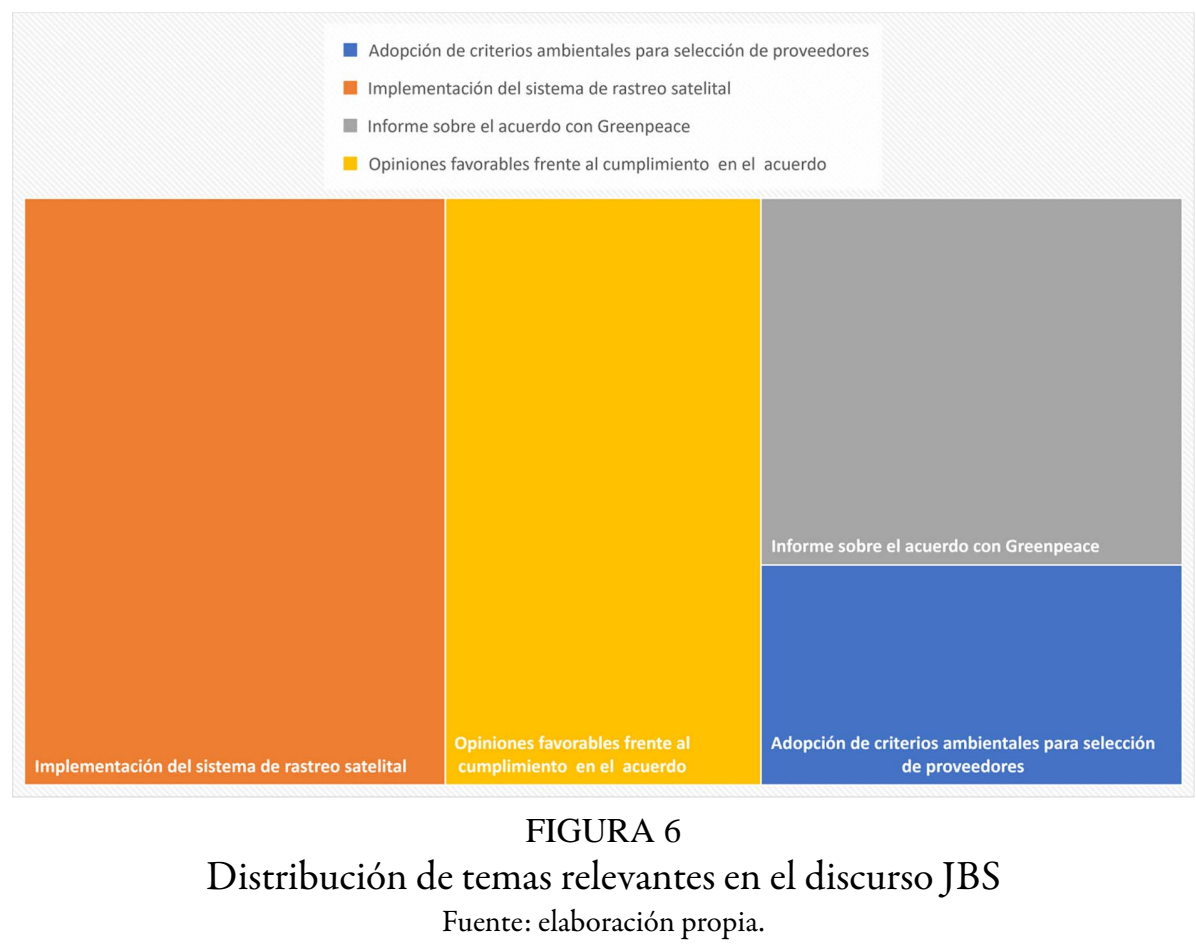

La figura 6 muestra los temas de mayor relevancia en los discursos oficiales de JBS y de sus auditores, en relación con sus implicaciones en la deforestación de la amazonía brasileña. Dentro de estos, la información oficial resalta la implementación del sistema de rastreo satelital para monitorear a los proveedores. Vale la pena aclarar que en este caso es evidente que el discurso omite que dicho sistema se enfoca en la vigilancia de proveedores directos. En segundo lugar, se encuentra la recurrencia de opiniones favorables por parte de los auditores contratados por JBS en relación con el cumplimiento de los acuerdos. Estas opiniones quedan seriamente cuestionadas por la contrainformación recolectada. No obstante, en todos los informes analizados los auditores aclaran que la verificación fue realizada apenas a una muestra no mayor al 15\% de las transacciones de JBS.

De acuerdo con Boiral (2013), los informes corporativos pueden camuflar problemas del desarrollo sostenible, tal como ha sucedido con JBS al reportar su comportamiento transparente y ético, postura contundentemente contrariada por amplificadores del tema, como los medios alternativos. Sin embargo, es más condenable que JBS insista en usar sus informes para sugerir una integridad moral (Adams, 2004). A su vez, este caso permite evidenciar cómo los informes de sostenibilidad preparados bajo estándares GRI son insuficientes para dar cuenta de la insostenibilidad de ciertas actividades económicas, sobre todo aquellas que representan altos riesgos para la biodiversidad, y no reflejan un cambio en las prácticas organizacionales puesto que, hasta la fecha, JBS sigue siendo relacionada con la deforestación (Boiral, 2013). En la misma línea de Bebbington (2001), la falta de responsabilidad de JBS en cuanto a la integridad de toda su cadena productiva se refleja en la manera como los informes de sostenibilidad se limitan a una parte de la actividad organizacional, ocultando prácticas de insostenibilidad detrás de sus compras indirectas.

Si se creyera lo informado por JBS, el público y demás actores de la arena continuarían confiando en que el sistema de monitoreo social y ambiental garantiza la protección de la biodiversidad, más aún si en el asunto intervino un auditor externo que avaló tal reporte; esto queda desvirtuado por el aumento de las tasas de deforestación en 2019. Este asunto confirma la importancia de las contracuentas de activistas y otros actores en el desafío y deslegitimación de las corporaciones (Thomson et al., 2010) y resalta de manera importante el valor de controvertir el discurso oficial. 


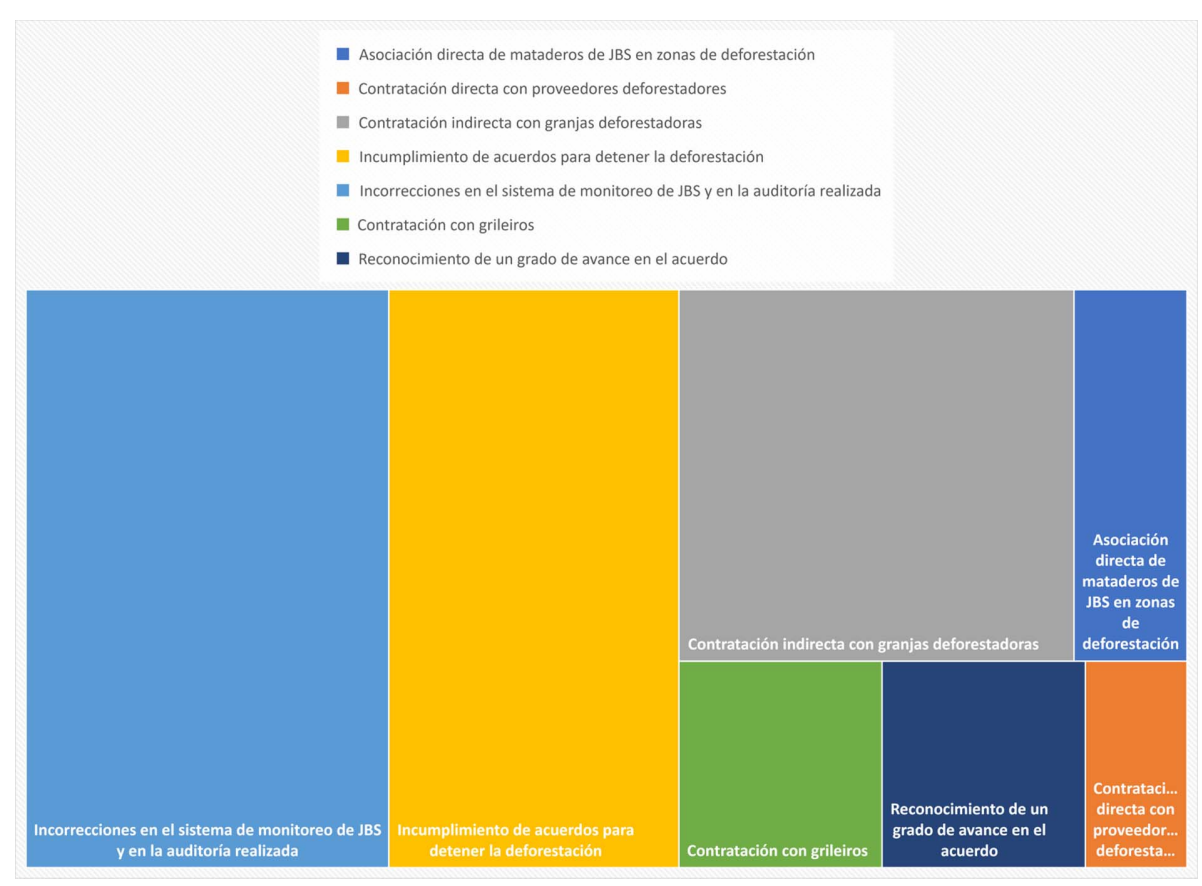

FIGURA 7

Distribución de temas relevantes en la contrainformación

Fuente: elaboración propia.

La figura 7 muestra los temas que tuvieron mayor relevancia dentro de la contracuenta en relación con la insostenibilidad de JBS frente a la deforestación de la amazonía brasileña. Como es evidente, las organizaciones externas enfatizaron tres grandes aspectos que controvierten la intención de JBS de construir una imagen de empresa sostenible, ética y transparente, a saber: las incorrecciones en el sistema de monitoreo, el incumplimiento de acuerdos para detener la deforestación y la contratación indirecta con granjas deforestadoras, que a su vez desmontan la opinión favorable de los auditores. Esto, no solamente cuestiona la información contable no financiera emitida por JBS, sino que nos permite mostrar la posibilidad de una contra-auditoría, basada en el control social, que tenga la capacidad de controvertir también a aquellos actores que ayudan a legitimar los discursos organizacionales y que empodere a la ciudadanía y le brinde herramientas desde la contabilidad y el control tan valiosas como las que puede otorgar la contabilidad tradicional (Cooper \& Morgan, 2013).

De hecho, en este caso fueron las fuentes externas quienes revelaron que JBS había comprado ganado a acaparadores y gracias a esta acción, es posible comprender que la actividad de esta organización no solo ocasionó de manera directa e indirecta pérdida de biodiversidad, sino que también generó efectos sociales derivados.

Así, el caso de JBS con su operación conflictiva y generación de impactos negativos de orden social y ambiental donde los actores pueden manifestarse de manera valiente, mediante la construcción de una contracontabilidad que permita presionar una transformación de la realidad, constata con Gallhofer la necesidad de una contabilidad habilitante que viabilice el rescate de una vida digna (Gallhofer \& Haslam, 1997).

\section{Conclusiones}

La pérdida de biodiversidad ha representado una preocupación para la contabilidad social y ambiental en tanto se ha reconocido que el actuar corporativo capitalista alimenta el despojo y la degradación (Ángel 
Maya, 2003; Boiral, 2016; Naredo, 2010). A pesar de que se ha planteado que los reportes de sostenibilidad emitidos bajo estándares como el GRI contribuyen a la transparencia y rendición de cuentas, la literatura ha señalado que han sido usados como medios de legitimación del actuar irresponsable, o como mecanismos de manipulación de las audiencias y de construcción de percepciones ocultando las voces de los verdaderos afectados.

Con ello, a pesar de que oficialmente se han difundido las bondades del desarrollo sostenible como un modelo que permite a las compañías obtener lucro de manera responsable, humana y ambiental, existen evidencias que demuestran su debilidad para atender los problemas de raíz. En los países denominados 'en vía de desarrollo’ persisten y se agudizan problemáticas sociales y ambientales que denotan la insostenibilidad del sistema capitalista. En este caso, la pérdida de biodiversidad como fruto de la deforestación en Brasil permite comprender que es necesario repensar el desarrollo, atendiendo a los límites de la naturaleza (Leff, 2008). Así, este trabajo puso en diálogo académico el pensamiento latinoamericano en materia ambiental con el desarrollo y avances de la contracontabilidad, para explorar un caso particular de insostenibilidad en Brasil desde un análisis crítico de sus discursos.

Una de las actividades económicas más riesgosas actualmente para el ambiente es la ganadería extensiva. Por ello, nuestro estudio ha resaltado que el sector ganadero es uno de los responsables de la deforestación en el mundo, lo que pone en jaque a las grandes compañías que lideran el sector. El caso particular de JBS fue emblemático para su análisis por cuanto sus acciones por más de diez años han repercutido de manera significativa en la pérdida de biodiversidad de Brasil, y con ello de una de las regiones con mayor riqueza natural. Mediante la construcción de una contracuenta que reunió las expresiones contestatarias de diversos actores de la arena en que opera JBS se evidenció la responsabilidad directa e indirecta que la misma tuvo en la deforestación en la Amazonía y que negaba según los reportes tradicionales (Boiral, 2013, 2016; Thomson et al., 2010).

Contrastar los informes de JBS por su desempeño, con la contrainformación de otros actores de la arena en que opera la compañía, ha permitido confirmar que la contracontabilidad es un mecanismo válido de las ONG - en este caso Greenpeace y otros- para promover reformas en procesos conflictivos de gobernanza y con desigualdades de poder (Denedo et al., 2017). Los informes contrahegemónicos llamaron la atención de diversos stakeholders y del público en general al punto de hacer que algunos de los clientes de la compañía cortaran relaciones comerciales con JBS. Fruto de esta información, organismos de vigilancia y control emprendieron acciones que llevaron al embargo de dos plantas de la compañía y a una multa.

De esta manera es claro que interlocutores válidos, confiables y con poder moral pudieron ejercer presión sobre JBS cuyo desempeño e informes propios no concuerdan con la realidad, dándose la posibilidad de útiles acuerdos que configuren una contabilidad dialógica, cuyo objetivo sea apoyar el cambio progresivo de situaciones indeseables (Brown \& Dillard, 2015).

El caso abordado en este estudio permitió realizar exploraciones sobre las falencias que los reportes de sostenibilidad presentan como instrumentos de rendición de cuentas y abre campo a investigaciones más profundas que aporten información alternativa para alcanzar la emancipación. Latinoamérica es escenario de múltiples conflictos sociales y ambientales, que la contabilidad tradicional no ha logrado plasmar en sus reportes, por lo que es indispensable que se emprendan estudios con la contracontabilidad para generar una transformación conveniente a los intereses de las grandes masas, de manera que se reconozca un sentido político de la contabilidad que nos permita reafirmar que las contracuentas también son contabilidad (Blackburn, Brown, Dillard et al., 2014; Gallhofer et al., 2010; Gray et al., 2014; Martínez-Alier, 2004).

Finalmente, como una limitación del estudio señalamos el alcance de los análisis y las interpretaciones que se circunscriben, en su aspecto empírico, solamente al caso JBS y que no pueden generalizarse a otras industrias similares ni a otros sectores. Por ello, hacemos un llamado para que estudios posteriores aborden trabajos en esta línea, ya sea con estudios de caso múltiples o con metodologías alternativas que aumenten la evidencia en este sentido. 


\section{Consideraciones éticas}

La investigación no requirió o no aval ético para su realización

\section{Contribución de los autores}

Los dos autores tuvieron un rol intelectual y operativo en la investigación. Ambos participaron activamente desde la concepción de la idea hasta su ejecución y en la posterior redacción de este documento.

\section{Financiación}

Este artículo fue financiado con recursos propios de la Universidad Nacional de Colombia y la Universidad Cooperativa de Colombia como parte del proyecto de investigación titulado "Tendencias y determinantes de los informes de sostenibilidad en Latinoamérica".

\section{Conflictos de interés}

Los autores no tienen ningún conflicto de interés asociado al desarrollo de la investigación y de la presentación de artículo.

\section{Referencias}

Adams, C. A. (2004). The ethical, social and environmental reporting-performance portrayal gap. Accounting, Auditing \& Accountability Journal, 17(5), 731-757. https://doi.org/10.1108/09513570410567791

Alvesson, M., \& Kärreman, D. (2011). Decolonializing discourse: Critical reflections on organizational discourse analysis. Human Relations, 64(9), 1121-1146. https://doi.org/10.1177/0018726711408629

Amazon Watch (2019). Complicity in destruction II: How northern consumers and financiers enable Bolsonaro's assault on the brazilian amazon.

Ángel Maya, A. (1996). La fragilidad ambiental de la cultura. Historia y Medio Ambiente.

Ángel Maya, A. (2003). La Diosa Némesis. Cali: Cargraphics S.A.

Ángel Maya, A. (2013). El Reto de la Vida. Ecosistema y Cultura. Una Introducción al Estudio del Medio Ambiente. Bogotá: Ecofondo.

Apostol, O. M. (2010). A project for Romania? The role of the civil society's counter- accounts in facilitating democratic change in society. Accounting, Auditing \& Accountability Journal, 28(2), 210-241. https://doi.org/10.1108/A AAJ-07-2012-01057

Atkins, J., \& Maroun, W. (2018). Integrated extinction accounting and accountability: building an ark. En Accounting, Auditing and Accountability Journal (Vol. 31). https://doi.org/10.1108/AAAJ-06-2017-2957

Bakan, J. (2006). La corporación: La búsqueda patológica de lucro y poder. Bogotá: Robinbook.

BBC (2017). Lo que se sabe del escándalo en Brasil con la carne podrida que era "maquillada" para ser exportada. Recuperado el 29 de enero de 2020 de https://www.bbc.com/mundo/noticias-america-latina-39327633

BDO (2016). Third-party audit report to meet undertaking to adopt «Public Commitment of Livestock» as indicated in the «minimum criteria for industrial-scale operations with cattle and beef products in the Amazon Biome».

Bebbington, J. (2001). Sustainable development: a review of the international development, business and accounting literature. Accounting Forum, 25(2), 128-157. https://doi.org/10.1111/1467-6303.00059 
Bebbington, J., \& Gray, R. (2001). An account of sustainability: Failure, success and a reconceptualization. Critical Perspectives on Accounting, 12(5), 557-587. https://doi.org/10.1006/cpac.2000.0450

Bebbington, J., \& Larrinaga, C. (2014). Accounting and sustainable development: An exploration. Accounting, Organizations and Society, 39(6), 395-413. https://doi.org/10.1016/j.aos.2014.01.003

Bebbington, J., Larrinaga, C., \& Moneva, J. M. (2008). Corporate social reporting and reputation risk management. Accounting, Auditing \& Accountability Journal, 21(3), 337-361. https://doi.org/10.1108/09513570810863932

Bebbington, J., \& Unerman, J. (2018). Achieving the United Nations Sustainable Development Goals: An enabling role for accounting research. Accounting, Auditing \& Accountability Journal, 31(1), 1592. https://doi.org/10.1 108/AAAJ-05-2017-2929

Blackburn, N., Brown, J., Dillard, J., \& Hooper, V. (2014). A dialogical framing of AIS-SEA design. International Journal of Accounting Information Systems, 15(2), 83-101. https://doi.org/10.1016/j.accinf.2013.10.003

Boiral, O. (2013). Sustainability reports as simulacra? A counter-account of A and A+ GRI reports. Auditing \& Accountability Journal, 26(7), 1036-1071. https://doi.org/10.1108/AAAJ-04-2012-00998

Boiral, O. (2016). Accounting for the Unaccountable: Biodiversity Reporting and Impression Management. Journal of Business Ethics, 135, 751-768. https://doi.org/10.1007/s10551-014-2497-9

Brown, J., \& Dillard, J. (2015). Dialogic Accountings for Stakeholders: On Opening Up and Closing Down Participatory Governance. Journal of Management Studies, 52(7), 961-985. https://doi.org/10.1111/joms.121 53

Cho, C. H., Laine, M., Roberts, R. W., \& Rodrigue, M. (2015). Organized hypocrisy, organizational façades, and sustainability reporting. Accounting, Organizations and Society, 40, 78-94. https://doi.org/10.1016/j.aos.2014. 12.003

Chua, W. F. (2009). Desarrollos radicales en el pensamiento contable. En M. Gómez Villegas \& C. Ospina Zapata (Eds.), Avances Interdisciplinarios para una comprensión crítica de la contabilidad: Textos paradigmáticos de las corrientes heterodoxas (p. 243). Medellín.

Cipullo, N. (2016). Biodiversity Indicators: The Accounting Point of View. Procedia Economics and Finance, 39(November 2015), 539-544. https://doi.org/10.1016/s2212-5671(16)30297-0

Climate Home News (2017). Troubled meatpacker JBS sanctioned over Amazon deforestation. Recuperado el 28 de enero de 2020 de https://www.climatechangenews.com/2017/03/31/troubled-meatpacker-jbs-sanctioned-am azon-deforestation/

Comisión Mundial del Medio ambiente y del Desarrollo (1988). Nuestro futuro común. Madrid: Alianza Editorial.

Conde, M. (2016). Resistance to Mining. A Review. Ecological Economics, 132, 80-90. https://doi.org/10.1016/j.ec olecon.2016.08.025

Contrafatto, M., Thomson, I., Monk, E. A. (2015). Peru, mountains and los niños: Dialogic action, accounting and sustainable transformation. Critical Perspectives on Accounting, 33, 117-136. https://doi.org/10.1016/j.cpa.201 5.04 .009

Cooper, C. (1992). The Non and Nom of Accounting for (M)other Nature. Accounting Auditing and Accountability, 5(3), 16-39. https://doi.org/10.1108/09513579210017361

Cooper, D. J., \& Morgan, W. (2013). Meeting the evolving corporate reporting needs of government and society: Arguments for a deliberative approach to accounting rule making. Accounting and Business Research, 43(4), 418-441. https://doi.org/10.1080/00014788.2013.794411

Cuckston, T. (2013). Bringing tropical forest biodiversity conservation into financial accounting calculation. Accounting, Auditing and Accountability Journal, 26(5), 688-714. https://doi.org/10.1108/AAAJ-02-2013-12 31

Cuckston, T. (2018). Making Accounting for Biodiversity Research a Force for Conservation. Social and Environmental Accountability Journal, 38(3), 218-226. https://doi.org/10.1080/0969160X.2018.1516559

De Venanzi, A. (2002). Globalización y corporación. El orden social en el siglo XXI. Barcelona: Anthropos. 
Decaëns, T., Martins, M. B., Feijoo, A., Oszwald, J., Dolédec, S., et al. (2018). Biodiversity loss along a gradient of deforestation in Amazonian agricultural landscapes. Conservation Biology, 32(6), 1380-1391. https://doi.org/1 $0.1111 /$ cobi.13206

Denedo, M., Thomson, I., \& Yonekura, A. (2017). International Advocacy NGOs, Counter Accounting, Accountability and Engagement. Accounting, Auditing \& Accountability Journal, 30(6), 1309-1343. https://do i.org/10.1108/AAAJ-03-2016-2468

DNV GL (2017a). Evaluation of Fulfilment of the «Public Livestock Commitment».

DNV GL (2017b). JBS divulga relatório que reafirma seu compromisso com o fim do desmatamento na Amazônia . Recuperado el 27 de enero de 2020 de https://www.dnvgl.com.br/news/jbs-divulga-relatorio-que-reafirma-seu -compromisso-com-o-fim-do-desmatamento-na-amazonia-105374

DNV GL (2018). Evaluation of Fulfilment of the "Public Livestock Commitment". http://jbsold.adttemp.com.br/wpcontent/uploads/2018/11/JBS_Public-Livestock-Commitment-Report-2018-DNVGL_EN.pdf

Dussel, E. (2001). Hacia una filosofia politica critica. Bilbao: Editorial Desclée de Brouwer.

EJAtlas (2018). Landless peasants of «KM Mil» against land grabbers in Novo Progresso, Pará, Brazil.

Escobar, A. (2007). La invención del tercer mundo: construcción y deconstrucción del desarrollo. Caracas: Fundación Editorial el perro y la rana.

Escobar, A. (2014a). La invención del desarrollo. Popayán: Universidad del Cauca.

Escobar, A. (2014b). Sentipensar con la tierra. Nuevas lecturas sobre desarrollo, territorio y diferencia. Medellín: Ediciones Unaula.

Estevan, A., \& Naredo, J. M. (2009). Por una economía ecológica y solidaria: conversaciones con Antionio Estevan y José Manuel Naredo. Barecelona: Icaria.

Euromeatnews.com. (2020). JBS to supply meat worth $\$ 717$ million to China. Recuperado el 29 de enero de 2020 de https://www.euromeatnews.com/Article-JBS-to-supply-meat-worth-\%24717-million-to-China/3556

FAOSTAT (2017). Existencias de ganadería a nivel mundial. Recuperado el 28 de enero de 2020 de http://www.fao .org/faostat/es/\#data/QA

Fearnside, P. (2017). Deforestation of the Brazilian Amazon. En H. Shugart (Ed.), Oxford Research Encyclopedia of Environmental Science. New York: Oxford University Press. https://doi.org/10.1093/acrefore/978019938941 4.013.102

Gallhofer, S., \& Haslam, J. (1997). Beyond accounting: The possibilities of accounting and "critical" accounting research. Critical Perspectives on Accounting, 8(1-2), 71-95. https://doi.org/10.1006/cpac.1996.0087

Gallhofer, S., \& Haslam, J. (2003). Accounting and emancipation. Some critical interventions. New York: Routledge.

Gallhofer, S., Haslam, J., Monk, E., \& Roberts, C. (2006). The emancipatory potential of online reporting: The case of counter accounting. International Journal of Educational Management, 20(7), 681-718. https://doi.org/10. $1108 / 09513570610689668$

Gallhofer, S., Haslam, J., \& Yonekura, A. (2010). Accounting as differentiated universal for emancipatory praxis: Accounting delineation and mobilisation for emancipation $(s)$ recognising democracy and difference.Accounting, Auditing \& Accountability Journal, 28(5), 846-874. https://doi.org/10.1108/AAAJ-08-2013-1451

Georgakopulos, G., \& Thomson, I. (2008). Social reporting, engagements, controversies and conflict in an arena context. Accounting, Auditing and Accountability Journal, 21(8), 1116-1143. https://doi.org/10.1108/095135 70810918788

Gibbs, H. K., Munger, J., L'Roe, J., Barreto, P., Pereira, R., Christie, M. et al. (2016). Did Ranchers and Slaughterhouses Respond to Zero-Deforestation Agreements in the Brazilian Amazon? Conservation Letters, 9(1), 32-42. https ://doi.org/10.1111/conl.12175

Global Reporting Initiative - GRI (2019). SDD - GRI Database. Recuperado el 9 de mayo de 2017 de http://datab ase.globalreporting.org/

Gorz, A. (2008). Critica de la razón productivista. Madrid: Catarata. 
Gray, R. (1992). Accounting And Environmentalism: An Exploration of the Challenge of Gently Accounting for Accountability, Transparency and Sustainability. Accounting, Organizations and Society, 17(5), 399-425. https: //doi.org/10.1016/0361-3682(92)90038-T

Gray, R. (2002). Privileging engagement, imaginings, new accountings and pragmatism over critique? Accounting, Organizations and Society, 27(7), 687-708. https://doi.org/10.1016/S0361-3682(00)00003-9

Gray, R. (2006). Social, environmental and sustainability reporting and organisational value creation?: Whose value? Whose creation? En Accounting, Auditing and Accountability Journal (Vol. 19). https://doi.org/10.1108/0951 3570610709872

Gray, R. (2010). Is accounting for sustainability actually accounting for sustainability...and how would we know? An exploration of narratives of organisations and the planet. Accounting, Organizations and Society, 35, 47-62. htt ps://doi.org/10.1080/0969160X.2011.556420

Gray, R., Brennan, A., \& Malpas, J. (2014). New accounts: Towards a reframing of social accounting. Accounting Forum, 38(4), 258-273. https://doi.org/10.1016/j.accfor.2013.10.005

Gray, R., Dillard, J., \& Spence, C. (2009). Social accounting research as if the world matters: An essay in postalgia and a new absurdismspi. Public Management Review, 11(5), 545-573. https://doi.org/10.1080/14719030902798222

Gray, R. (1994). Corporate Reporting for Sustainable Development: Accounting for Sustainability in 2000AD. Environmental Values, 3(1), 17-45. https://doi.org/10.3197/096327194776679782

Gray, R., \& Milne, M. (2002). Towards reporting on the triple bottom line: Mirages, methods and myths. En R. Editors (Ed.), Towards reporting on the triple bottom line: Mirages, Methods and Myths Professor (pp. 70-80). London.

Greenpeace (2009a). Farra do boi na amzonia. http://greenpeace.org.br/gado/farradoboinaamazonia.pdf

Greenpeace (2009b). MINIMUM CRITERIA FOR INDUSTRIAL SCALE CATTLE OPERATIONS IN THE BRAZILIAN AMAZON BIOME .

Greenpeace (2009c). Slaughtering the Amazon. Recuperado de www.greenpeace.org

Greenpeace (2012). JBS recommits to Cattle Agreement in the Amazon. Recuperado 28 de enero de 2020 de https:/ /www.greenpeace.org/usa/jbs-recommits-to-cattle-agreement-in-the-amazon/

Greenpeace (2015). Carne ao Molho Madeira.

Greenpeace (2017). Greenpeace Brazil Suspends Negotiations with Cattle Giant JBS. Recuperado 28 de enero de 2020, de https://www.greenpeace.org/usa/news/greenpeace-brazil-suspends-negotiations-cattle-giant-jbs/

Greenpeace (2020). Amazonas. Recuperado el 27 de enero de 2020 de https://es.greenpeace.org/es/trabajamos-en/ bosques/amazonas/

Hahn, R., \& Lülfs, R. (2014). Legitimizing Negative Aspects in GRI-Oriented Sustainability Reporting: A Qualitative Analysis of Corporate Disclosure Strategies. Journal of Business Ethics, 123(3), 401-420. https://doi.org/10.10 07/s10551-013-1801-4

JBS S.A. (2012). Relatório anual e de sustentabilidade 2011. São Paulo. Recuperado de http://www.abifa.com.br

JBS S.A. (2013). Relatório Anual e de Sustentabilidade Annual and Sustainability Report 2012. São Paulo. https://jb s.com.br/sustentabilidade/ras/relatorios/

JBS S.A. (2017). Avaliação ao Atendimento do Compromisso Público da Pecuária na Amazônia. Sao Paulo.

JBS S.A. (2019a). Annual and Sustainability Report 2018. https://jbs.com.br/wp-content/uploads/2019/11/JBS_R AS2018_book_EN.pdf

JBS S.A. (2019b). History. Recuperado el 27 de enero de 2020 de https://jbss.infoinvest.com.br/jbs/history?idioma $=$ enu

Jiménez, F. (2008). La sexta extinción: La mayor amenaza de la tierra es la humanidad. Barcelona: Editorial Planeta.

Jones, M. J. (1996). Accounting for biodiversity: A pilot study. British Accounting Review, 28(4), 281-303. https://d oi.org/10.1006/bare.1996.0019

Jones, M. J. (2003). Accounting for biodiversity: operationalising environmental accounting. Accounting, Auditing \& Accountability Journal, 16(5), 762-789. https://doi.org/10.1108/09513570310505961 
Jones, M., Jones, M., \& Solomon, J. (2013). Problematising accounting for biodiversity. Accounting, Auditing \& Accountability Journal, 26(5), 668-687. https://doi.org/10.1108/AAAJ-03-2013-1255

Khan, T. (2014). Kalimantan's biodiversity: Developing accounting models to prevent its economic destruction. Accounting, Auditing and Accountability Journal, 27(1), 150-182. https://doi.org/10.1108/AAAJ-07-2013-13 92

Lamberton, G. (2005). Sustainability accounting - A brief history and conceptual framework. Accounting Forum, 29(1), 7-26. https://doi.org/10.1016/j.accfor.2004.11.001

Lanka, S. V., Khadaroo, I., \& Böhm, S. (2017). Agroecology accounting: biodiversity and sustainable livelihoods from the margins. Accounting, Auditing and Accountability Journal, 30(7), 1592-1613. https://doi.org/10.1108/AA AJ-12-2015-2363

Latouche, S. (2008). La apuesta por el decrecimiento: Cómo salir del imaginario dominante? Barcelona: Icaria.

Leff, E. (1986). Ecologia y Capital. Hacia una perspectiva ambiental del desarrollo (Primera). México: Universidad Nacional Autónoma de México.

Leff, E. (2002). Saber ambiental: sustentabilidad, racionalidad, complejidad, poder. Siglo XXI.

Leff, E. (2008). Discursos sustentables: Ambiente y democracia. México DF: Siglo XXI Editores.

Lehman, C., Marcia, A., \& Agyemang, G. (2016). Immigration and neoliberalism: three cases and counter accounts. Accounting Auditing and Accountability Journal, 29(1). https://doi.org/10.1108/AAAJ-09-2013-1470

Maroun, W., \& Atkins, J. (2018). The emancipatory potential of extinction accounting: Exploring current practice in integrated reports. Accounting Forum, 42(1), 102-118. https://doi.org/10.1016/j.accfor.2017.12.001

Martínez-Alier, J. (2004). Los conflictos ecológico- distributivos y los indicadores de sustentabilidad. Revista Iberoamericana de economia ecológica (REVIBEC), 1, 21-30. https://doi.org/10.4000/polis.5359

Max-Neef, M., \& Smith, P. (2014). La economía desenmascarada: Del poder y la codicia a la compasión y el bien común. Barcelona: Icaria.

Meadows, D., Meadows, D., Randers, J., \& Behrens, W. (1976). Los limites del crecimiento. México DF: Fondo de Cultura Económica.

Merkl-Davies, D., \& Brennan, N. (2007). Discretionary disclosure strategies in corporate narratives\#: incremental information or impression management? Journal of Accounting Literature, 26, 116-196. http://hdl.handle.net $/ 10197 / 2907$

Mighty Earth (2019). The Companies Behind the Burning of the Amazon. Recuperado el 29 de enero de 2020 de $h$ ttps://stories.mightyearth.org/amazonfires/index.html

Moneva, J. M., Archel, P., \& Correa, C. (2006). GRI and the camouflaging of corporate unsustainability. Accounting Forum, 30, 121-137. https://doi.org/10.1016/j.accfor.2006.02.001

Mongabay Latam (2019). Brasil: empresas multadas por deforestación amazónica continúan haciendo negocios con China, Europa y Estados Unidos. Recuperado 29 de enero de 2020 de https://es.mongabay.com/2019/08/bras il-deforestacion-negocios-china-europa-estados-unidos/

Müller, E. (2020, enero). La pérdida de diversidad biológica nos sacará del planeta antes que el cambio climático. Pais Circular.

Myers, N., Mittermeier, R., Mittermeie, C., Fonseca, G. da, \& Kent, J. (2000). Biodiversity hotspots for conservation priorities. Nature, 403, 853-858. https://doi.org/10.1038/35002501

Naredo, J. (2010). Raices económicas del deterioro ecológico y social: Más allá de los dogmas. Madrid: Siglo XXI Editores.

National Geographic (2019). What the Amazon fires mean for wild animals. Recuperado el 29 de enero de $2020 \mathrm{de}$ https://www.nationalgeographic.com/animals/2019/08/how-the-amazon-rainforest-wildfires-will-af fect-wild-animals/

Noguera, A. P. (2004). El reencantamiento del mundo. México DF: PNUMA y Universidad Nacional de Colombia.

Paisey, C., \& Paisey, N. J. (2006). The internet and possibilities for counter accounts: Some reflections: A reply. International Journal of Educational Management, 20(7), 774-778. https://doi.org/10.1108/0951357061068 9703 
Piketty, T. (2014). El capital en el siglo XXI, $1^{\text {a }}$ ed. Bogotá: Fondo de Cultura Económica.

Quijano, A. (2014). Cuestiones y horizontes. Antología Esencial de la dependencia histórico-estructural a la colonialidad/ descolonialidad del poder. Buenos Aires: CLACSO.

Renn, O. (1992). The Social Arena Concept of Risk Debates. En S. Krimsky \& D. Golding (Eds.), Social Theories of Risk (pp. 179-196). Praeger Publisher.

Repórter Brasil (2015). JBS compro gado da família do maior desmatador da Amazonia. Recuperado 28 de enero de 2020, de https://da-floresta-a-mesa.webflow.io/

Reuters. (2020).JBS SA Profile . Recuperado 27 de enero de 2020 de https://www.reuters.com/companies/JBSS3.SA

Richardson, A. J. (2009). La contabilidad como una institución de legitimación. En M. Gómez Villegas \& C. M. Ospina Zapata (Eds.), Avances interdisciplinarios para una comprensión critica de la contabilidad: Textos paradigmáticos de las corrientes heterodoxas (p. 243). Medellín: Universidad Nacional de Colombia y Universidad de Antioquia.

Ryan, B., Scapens, R., \& Theobald, M. (2004). Metodología de la investigación en finanzas y contabilidad. Deusto.

Sikka, P. (2006). The internet and possibilities for counter accounts: some reflections. Accounting, Auditing \& Accountability Journal, 19(5), 759-769. https://doi.org/10.1108/09513570610689686

Spence, C. (2009). Social accounting's emancipatory potential: A Gramscian critique. Critical Perspectives on Accounting, 20(2), 205-227. https://doi.org/10.1016/j.cpa.2007.06.003

Spence, C., Husillos, J., \& Correa-Ruiz, C. (2010). Cargo cult science and the death of politics: A critical review of social and environmental accounting research. Critical Perspectives on Accounting, 21(1), 76-89. https://doi.org /10.1016/j.cpa.2008.09.008

Taibo, C. (2010). Decrecimientos: sobre lo que hay que cambiar en la vida cotidiana. Madrid: Catarata.

Teitelbaum, A. (2010). La armadura del capitalismo. El poder de las sociedades trasnacionales en el mundo contemporáneo. Barcelona: Icaria.

The Guardian. (2012). Tesco supplier accused of contributing to Amazon rainforest destruction. The Guardian. http s://www.theguardian.com/environment/2012/jun/06/tesco-supplier-amazon-rainforest-destruction

The Guardian (2019). The swashbuckling meat tycoons who nearly brought down a government. The Guardian. Recuperado el 29 de enero de 2020 de https://www.theguardian.com/environment/2019/jul/02/swashbuckli ng-meat-tycoons-nearly-brought-down-a-government-brazil

The Guardian, The Bureau of Investigative Journalism, y Repórter Brasil (2020, julio). Brazilian meat giant trucked cattle from deforested Amazon ranch. Recuperado 18 de agosto de 2021 de https://www.thebureauinvestigates .com/stories/2020-07-27/brazilian-meat-giant-jbs-trucked-cattle-from-deforested-amazon-ranch

Thomson, I., Dey, C., \& Russell, S. (2010). Activism, arenas and accounts in conflicts over tobacco control. Accounting, Auditing \& Accountability Journal, 28(5), 809-845. https://doi.org/10.1108/AAAJ-08-2013-1439

Tinker, T., \& Gray, R. (2003). Beyond a critique of pure reason: From policy to politics to praxis in environmental and social research. En Accounting, Auditing \& Accountability Journal (Vol. 16). https://doi.org/10.1108/095 13570310505952

Tombs, S., \& Whyte, D. (2015). La empresa criminal. Por qué las corporaciones deben ser abolidas. Barcelona: Icaria.

Turner, P. A. M., Ximenes, F. A., Penman, T. D., Law, B. S., Waters, C. M. et al. (2019). Accounting for biodiversity in life cycle impact assessments of forestry and agricultural systems-the BioImpact metric. En International Journal of Life Cycle Assessment (Vol. 24). https://doi.org/10.1007/s11367-019-01627-5

UNEP - UN Environment Programme (2019). Statement by Inger Andersen on the ongoing fires in the Amazon rainforest . Recuperado el 29 de enero de 2020 de https://www.unenvironment.org/news-and-stories/stateme $\mathrm{nt} /$ statement-inger-andersen-ongoing-fires-amazon-rainforest

USDA (2020). Meat, Beef and Veal \%World Exports. Recuperado el 28 de enero de 2020 de https://apps.fas.usda.go v/psdonline/app/index.html\#/app/topCountriesByCommodity

Vinnari, E., \& Laine, M. (2017). The moral mechanism of counter accounts: The case of industrial animal production. Accounting, Organizations and Society, 57, 1-17. https://doi.org/10.1016/j.aos.2017.01.002 


\section{Anexo}

TABLA A1

Aspectos más relevantes encontrados en el discurso oficial de JBS

\begin{tabular}{|c|c|c|c|c|c|c|c|c|c|c|}
\hline $\begin{array}{l}\text { Aspectos más } \\
\text { relevantes }\end{array}$ & $\begin{array}{c}\text { JBS } \\
\text { (2011) }\end{array}$ & $\begin{array}{c}\text { JBS } \\
\text { (2012) }\end{array}$ & $\begin{array}{c}\text { JBS } \\
\text { (2017) }\end{array}$ & $\begin{array}{c}\text { BDO } \\
\text { (2013) }\end{array}$ & $\begin{array}{c}\text { BDO } \\
\text { (2014) }\end{array}$ & $\begin{array}{l}\text { BDO } \\
\text { (2016) }\end{array}$ & $\begin{array}{c}\text { DNV } \\
\text { GL } \\
(2017 a)\end{array}$ & $\begin{array}{c}\text { DNV } \\
\text { GL } \\
(\mathbf{2 0 1 7 b})\end{array}$ & $\begin{array}{c}\text { DNV } \\
\text { GL } \\
\text { (2018) }\end{array}$ & Total \\
\hline $\begin{array}{l}\text { Adopción de } \\
\text { criterios } \\
\text { ambientales } \\
\text { para selección } \\
\text { de proveedores }\end{array}$ & 1 & 1 & 1 & & & & & & & 3 \\
\hline $\begin{array}{l}\text { Implementación } \\
\text { del sistema de } \\
\text { rastreo satelital }\end{array}$ & & 1 & 1 & 1 & 1 & 1 & 1 & 1 & 1 & 8 \\
\hline $\begin{array}{l}\text { Informe sobre } \\
\text { el acuerdo con } \\
\text { Greenpeace } \\
\text { para detener la } \\
\text { deforestación }\end{array}$ & & & & 1 & 1 & & 1 & 1 & 1 & 5 \\
\hline $\begin{array}{l}\text { Opiniones } \\
\text { favorables } \\
\text { frente al } \\
\text { cumplimiento o } \\
\text { avance en el } \\
\text { acuerdo }\end{array}$ & & & & 1 & 1 & 1 & 1 & 1 & 1 & 6 \\
\hline
\end{tabular}

Fuente: elaboración propia

TABLA A2

Aspectos más relevantes encontrados en la contrainformación

\begin{tabular}{|c|c|c|c|c|c|c|c|}
\hline $\begin{array}{l}\text { Aspectos más } \\
\text { relevantes en } \\
\text { la } \\
\text { información } \\
\text { externa }\end{array}$ & $\begin{array}{l}\text { Mataderos } \\
\text { de JBS en } \\
\text { zonas de } \\
\text { deforesta- } \\
\text { ción }\end{array}$ & $\begin{array}{l}\text { Contrata- } \\
\text { ción } \\
\text { directa con } \\
\text { granjas } \\
\text { deforesta- } \\
\text { doras }\end{array}$ & $\begin{array}{l}\text { Contrata- } \\
\text { ción } \\
\text { indirecta } \\
\text { con } \\
\text { granjas } \\
\text { deforesta- } \\
\text { doras }\end{array}$ & $\begin{array}{l}\text { Incumpli- } \\
\text { miento de } \\
\text { acuerdos }\end{array}$ & $\begin{array}{l}\text { Incorrec- } \\
\text { ciones en } \\
\text { el sistema } \\
\text { de } \\
\text { monitoreo } \\
\text { y en la } \\
\text { auditoría }\end{array}$ & $\begin{array}{l}\text { Contrata- } \\
\text { ción con } \\
\text { grileiros }\end{array}$ & $\begin{array}{l}\text { Recono- } \\
\text { cimiento } \\
\text { de avance } \\
\text { en el } \\
\text { acuerdo }\end{array}$ \\
\hline $\begin{array}{l}\text { Greenpeace } \\
(2009 \mathrm{a})\end{array}$ & & & 1 & & 1 & & \\
\hline $\begin{array}{l}\text { Greenpeace } \\
(2009 b)\end{array}$ & 1 & & & & & & \\
\hline $\begin{array}{l}\text { Greenpeace } \\
\text { (2012) }\end{array}$ & & & & 1 & 1 & & \\
\hline $\begin{array}{l}\text { Repórter } \\
\text { Brasil (2015) }\end{array}$ & & & 1 & & 1 & & \\
\hline $\begin{array}{l}\text { Greenpeace } \\
(2015)\end{array}$ & & & & & & & 1 \\
\hline $\begin{array}{l}\text { Gibbs et al. } \\
\text { (2016) }\end{array}$ & & & & & 1 & & 1 \\
\hline $\begin{array}{l}\text { IBAMA } \\
(2017)\end{array}$ & & & 1 & 1 & 1 & & \\
\hline $\begin{array}{l}\text { Greenpeace } \\
\text { (2017a) }\end{array}$ & & & & 1 & 1 & & \\
\hline $\begin{array}{l}\text { Greenpeace } \\
(2017 b)\end{array}$ & & & & 1 & 1 & & \\
\hline $\begin{array}{l}\text { Climate } \\
\text { Home News } \\
(2017)\end{array}$ & & & & 1 & 1 & 1 & \\
\hline $\begin{array}{l}\text { Fernside } \\
(2017)\end{array}$ & & & 1 & 1 & 1 & & \\
\hline $\begin{array}{l}\text { EJAtlas } \\
(2018)\end{array}$ & & & 1 & 1 & & 1 & \\
\hline $\begin{array}{l}\text { Amazon } \\
\text { Watch (2019) }\end{array}$ & & 1 & 1 & 1 & & & \\
\hline $\begin{array}{l}\text { Mighty Earth } \\
\text { (2019) }\end{array}$ & 1 & & & & & & \\
\hline $\begin{array}{l}\text { The Guardian } \\
\text { et al. (2020) }\end{array}$ & & & 1 & & 1 & & \\
\hline Total & 2 & 1 & 7 & 8 & 10 & 2 & 2 \\
\hline
\end{tabular}

Fuente: elaboración propia.

\section{Notas}

* Artículo de investigación

Licencia Creative Commons CC BY 4.0

Sugerencia de citación: Valenzuela-Jiménez, L. F., \& Suárez-Rico, Y. M. (2021). La contabilidad del desarrollo insostenible. Un análisis de contracuentas sobre la pérdida de biodiversidad en el caso JBS Brasil. Cuadernos 